Article

\title{
Effect of Praziquantel on Schistosoma mekongi Proteome and Phosphoproteome
}

\author{
Peerut Chienwichai ${ }^{1}{ }^{(1)}$, Sumate Ampawong ${ }^{2}{ }^{\circ}$, Poom Adisakwattana ${ }^{3}$, \\ Tipparat Thiangtrongjit ${ }^{4}$, Yanin Limpanont ${ }^{5}$, Phiraphol Chusongsang ${ }^{5}$, Yupa Chusongsang ${ }^{5}$ \\ and Onrapak Reamtong $4, *$ (D) \\ 1 Faculty of Medicine and Public Health, HRH Princess Chulabhorn College of Medical Science, \\ Chulabhorn Royal Academy, Bangkok 10210, Thailand; peerut.chi@pccms.ac.th \\ 2 Department of Tropical Pathology, Faculty of Tropical Medicine, Mahidol University, \\ Bangkok 10400, Thailand; sumate.aum@mahidol.ac.th \\ 3 Department of Helminthology, Faculty of Tropical Medicine, Mahidol University, Bangkok 10400, Thailand; \\ poom.adi@mahidol.ac.th \\ 4 Department of Molecular Tropical Medicine and Genetics, Faculty of Tropical Medicine, Mahidol University, \\ Bangkok 10400, Thailand: tipparat.thi@mahidol.ac.th \\ 5 Department of Social and Environmental Medicine, Faculty of Tropical Medicine, Mahidol University, \\ Bangkok 10400, Thailand; yanin.lim@mahidol.ac.th (Y.L.); phiraphol.chu@mahidol.ac.th (P.C.); \\ yupa.chu@mahidol.ac.th (Y.C.) \\ * Correspondence: onrapak.rea@mahidol.ac.th
}

Received: 19 April 2020; Accepted: 25 May 2020; Published: 27 May 2020

\begin{abstract}
Schistosoma mekongi causes schistosomiasis in southeast Asia, against which praziquantel (PZQ) is the only treatment option. PZQ resistance has been reported, thus increasing the requirement to understand mechanism of PZQ. Herein, this study aimed to assess differences in proteome and phosphoproteome of S. mekongi after PZQ treatment for elucidating its action. Furthermore, key kinases related to PZQ effects were predicted to identify alternative targets for novel drug development. Proteomes of $S$. mekongi were profiled after PZQ treatment at half maximal inhibitory concentration and compared with untreated worms. A total of 144 proteins were differentially expressed after treatment. In parallel, immunohistochemistry indicated a reduction of phosphorylation, with 43 phosphoproteins showing reduced phosphorylation, as identified by phosphoproteomic approach. Pathway analysis of mass spectrometric data showed that calcium homeostasis, worm antigen, and oxidative stress pathways were influenced by PZQ treatment. Interestingly, two novel mechanisms related to protein folding and proteolysis through endoplasmic reticulum-associated degradation pathways were indicated as a parasiticidal mechanism of PZQ. According to kinase-substrate predictions with bioinformatic tools, Src kinase was highlighted as the major kinase related to the alteration of phosphorylation by PZQ. Interfering with these pathways or applying Src kinase inhibitors could be alternative approaches for further antischistosomal drug development.
\end{abstract}

Keywords: Schistosoma mekongi; praziquantel; proteomics; phosphoproteomics; endoplasmic reticulum-associated degradation; Src kinase

\section{Introduction}

Schistosomiasis, also known as bilharzia, is a neglected tropical disease that infects over 200 million people worldwide each year, resulting in 200,000 deaths [1,2]. Schistosoma mekongi is the causative agent of intestinal schistosomiasis in the lower Mekong river region, especially in Laos and northern Cambodia [1]. Infections in other parts of the world are occasionally reported owing to human 
migration and travel-related illness [3-5]. Clinical manifestations of Mekong schistosomiasis include abdominal pain, bloody stool, diarrhea and liver enlargement, resulting in fatality in severe cases $[1,6]$.

The only drug currently available for the treatment and prevention of $S$. mekongi is praziquantel (PZQ) $[7,8]$. PZQ has long been considered the drug of choice for schistosomiasis [7]. It has been extensively used for the treatment and control of blood fluke infections and other parasitic diseases for both medical and veterinary purposes $[7,9]$. PZQ shows excellent efficacy against various species of worm; however, drug resistance and low susceptibility of parasites have been recently observed $[10,11]$. PZQ resistance has been reported in various species of worms, including S. mansoni [12,13], S. japonicum [14], S. hematobium [15] and other cestode species [16,17]. For blood flukes, PZQ is effective only on adult and cercarial stage worms, while juvenile stage schistosomulae can retain viability after chemotherapy and progress to adulthood $[18,19]$. In addition, PZQ shows no protection against re-infection, making disease control difficult in high endemic areas [18]. To overcome these problems, a thorough understanding of the mechanism of action of PZQ is required and novel drug targets should be studied. Many hypotheses have been proposed to explain the helminthotoxic effect of PZQ in several Schistosoma species; for example, interference of cellular calcium homeostasis [20-22], damaging the tegument and exposure of worm antigen to host immunity $[20,22,23]$ and induction of oxidative stress [22,24]. Alterations in protein phosphorylation may also be one of the effects of PZQ in blood fluke killing; however, only a few studies have focused on this [25]. Differential protein phosphorylation throughout development has been detected using anti-phospho antibodies, suggesting the importance of phosphorylation in S. mansoni [26]. Moreover, sub-lethal dose of PZQ induced over-expression of $\mathrm{Ca}^{2+} /$ calmodulin-dependent protein kinase II (CamKII), key kinase for calcium homeostasis, indicating the possible link between the drug and phosphorylation [27]. Information on the effect of PZQ on protein phosphorylation in Schistosoma parasites would fill the knowledge void on the mechanism of action of this drug as well as providing some clues for future drug development targeting protein phosphorylation.

Phosphorylation is an important modification of proteins that play fundamental roles in the regulation of cellular metabolism, growth and division. Changes in phosphorylation levels can critically impact the functions proteins thereby reducing the survivability of organisms. Modern mass spectrometric (MS) technologies and phosphoprotein enrichment methods have been successfully used to elucidate the mechanism of action of a number of drugs, such as gemcitabine [28], midostaurin [29] and pyrazolo [3,4-d] pyrimidine [30]. The aim of this study was to apply proteomic and phosphoproteomic approaches to understand the mechanism of action of PZQ in S. mekongi. Moreover, the integration of phosphoproteomic and bioinformatics data can be used to predict the main kinases that control and alter of the phosphoproteome. The findings of this study could lead to a better understanding of the molecular action of PZQ in schistosome. In addition, the key kinases affected by PZQ exposure may be potential targets for antischistosomal drug development.

\section{Results}

\subsection{Anthelmintic Assay of PZQ on S. mekongi}

To examine the effective dose of PZQ for parasiticide activity on S. mekongi, adult worms were exposed to various concentrations of PZQ for $60 \mathrm{~min}$ and worm viability was assessed by observing the movement of the worms under a video microscope. PZQ at 0 and $20 \mu \mathrm{g} / \mathrm{mL}$ had no effect with all worms moving periodically (Video S1). After $40 \mu \mathrm{g} / \mathrm{mL}-\mathrm{PZQ}$ treatment, only half of the worms moved, indicating some parasiticidal activity (Figure 1, Video S2). At PZQ doses higher than $40 \mu \mathrm{g} / \mathrm{mL}$, all worms were killed (no movement observed). A PZQ concentration of $40 \mu \mathrm{g} / \mathrm{mL}$ killed $46.7 \%$ of adult worms and was defined as $\mathrm{IC}_{50}$. Worms treated with $40 \mu \mathrm{g} / \mathrm{mL}-\mathrm{PZQ}$ were further investigated for protein expression alteration. 


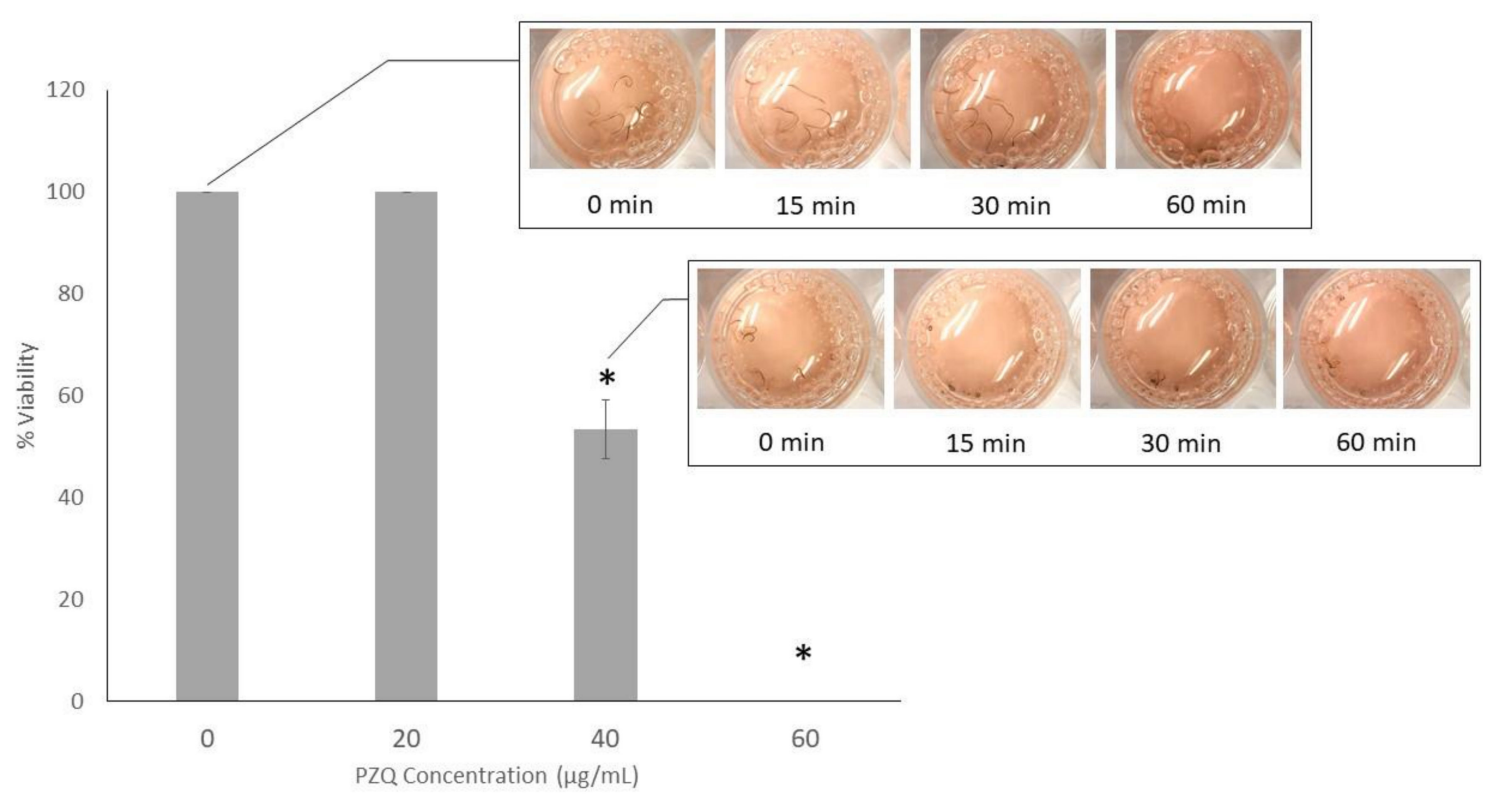

Figure 1. The $40 \mu \mathrm{g} / \mathrm{mL}$ concentration of praziquantel (PZQ) reduced viability of the worms by approximately $46.7 \%$. S. mekongi were treated with increasing concentration of PZQ for an hour and parasites without movement for a minute were assumed as dead. Bar chart represents percentage of viable S. mekongi after PZQ treatment. Asterisk shows statistical significance ( $p$ value $<0.05$ ).

\subsection{Effects of PZQ on S. mekongi Proteome}

The proteomic approach identified 1076 S. mekongi proteins in which 144 proteins were differentially expressed after PZQ treatment. The abundance of 68 proteins increased (Table S1), while 76 proteins decreased (Table S2). Gene ontology analysis of differential proteins was performed using BLAST2GO bioinformatic software. According to the biologic process term, most differentially expressed proteins are involved in redox processes $(18 \%)$ and proteolysis (15\%) (Figure 2A). However, using a molecular function term indicated that the proteins mainly correlated to metal-ion (32\%) and ATP binding (25\%) (Figure 2B). In the cellular component term, most of the altered proteins related to integral membrane $(34 \%)$ and cytoskeletal components (25\%) (Figure 2C). The top twenty up- and downregulated S. mekongi proteins after PZQ treatment are shown in Tables 1 and 2, respectively. Proteins related to structure, energy, protease, antioxidant, transcription and translation and antigens were highly upregulated after PZQ exposure. The structural protein paramyosin was the most upregulated protein with 5.96-fold change after treatment. However, some proteins involved in structure, energy, stress response and signaling were highly downregulated. The energy metabolism protein aldehyde dehydrogenase 1B1 precursor was the most downregulated protein after PZQ exposure (4-fold decrease). Interestingly, while none of kinases were found to be highly upregulated, there was a significant number of kinases showing decreased expression after PZQ treatment, such as pyruvate kinase PKM (A0A095B084: 2.38-fold decrease), arginine kinase (C1LFZ8: 2.27-fold decrease) and inositol hexakisphosphate and diphosphoinositol-pentakisphosphate kinase 2 (A0A095ASB2: 2-fold decrease) (Table 2). 
A.

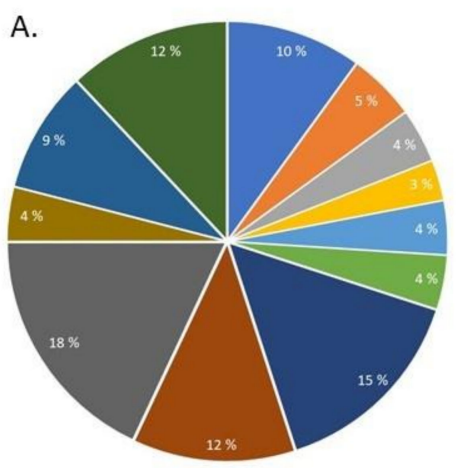

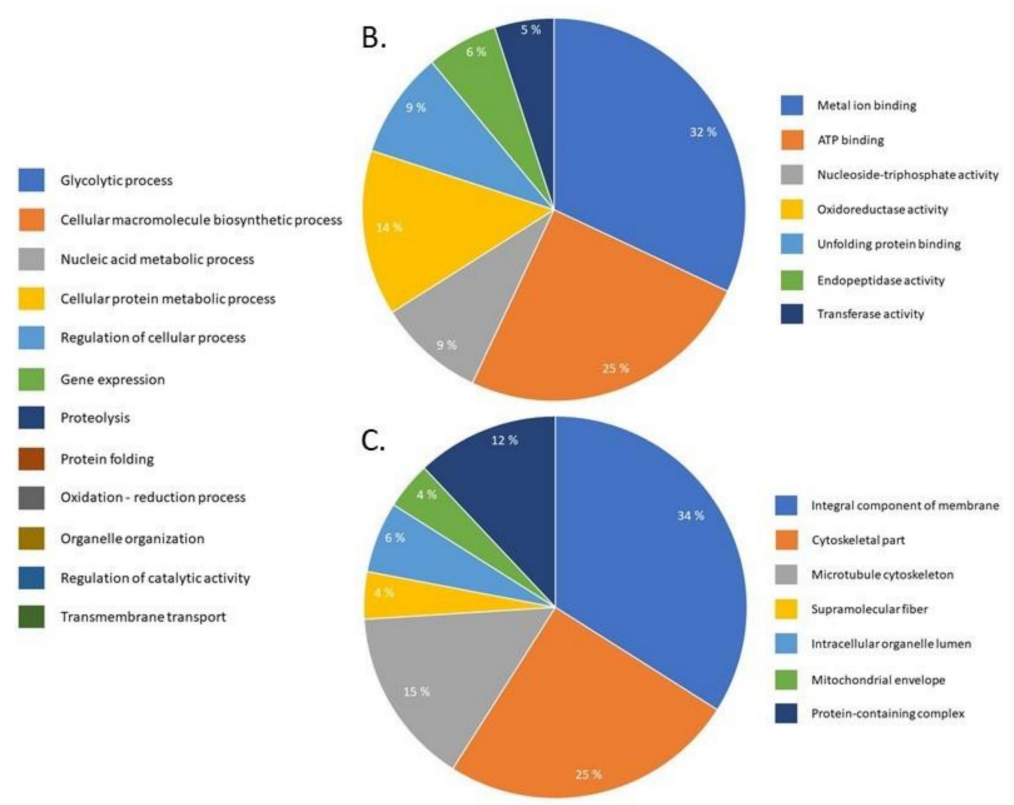

Figure 2. Gene ontology classification of S. mekongi proteomic data after PZQ treatment. The Differential proteins after PZQ exposure were classified according to their gene ontology using Blast2Go. Three terms of gene ontologies including (A) biologic process, (B) molecular function, and (C) cellular component are presented.

Table 1. Top-20 S. mekongi proteins upregulated after $40 \mu \mathrm{g} / \mathrm{mL}-\mathrm{PZQ}$ treatment.

\begin{tabular}{|c|c|c|c|c|c|c|c|}
\hline No. & $\begin{array}{l}\text { Accession No. } \\
\text { Uniprot }\end{array}$ & Protein Name & MW & pI & $\begin{array}{l}\text { Protein } \\
\text { Score }\end{array}$ & $\begin{array}{l}\text { Sequence } \\
\text { Coverage }\end{array}$ & $\begin{array}{c}\text { Average } \\
\text { Fold-Change }\end{array}$ \\
\hline \multicolumn{8}{|c|}{ Structural protein } \\
\hline 1 & Q9Y1U7 & Myosin light chain & 18.3 & 4.5 & 37 & 31.3 & 2 \\
\hline 2 & Q26507 & Paramyosin, partial & 51.6 & 5.03 & 522 & 46 & 5.96 \\
\hline 3 & Q26595 & Alpha tubulin & 49.9 & 4.97 & 104 & 17.5 & -1 \\
\hline \multicolumn{8}{|c|}{ Energy } \\
\hline 4 & A0A094ZC89 & $\begin{array}{c}\text { L-lactate } \\
\text { dehydrogenase } \\
\text { A chain }\end{array}$ & 32.7 & 6.75 & 97 & 19.6 & 2 \\
\hline 5 & G4VP51 & $\begin{array}{c}\text { Putative ADP, } \\
\text { ATP carrier protein }\end{array}$ & 29.9 & 9.47 & 518 & 48.2 & 2.29 \\
\hline 6 & C1LV81 & Aldolase & 39.5 & 6.56 & 447 & 53.4 & 3.27 \\
\hline 7 & A0A095AJN4 & Enolase & 46.6 & 6.34 & 130 & 27.9 & 2.56 \\
\hline \multicolumn{8}{|c|}{ Protease } \\
\hline 8 & C1L5C5 & $\begin{array}{c}\text { Putative } \\
\text { aminopeptidase } \\
\text { W07G4.4 }\end{array}$ & 56.2 & 7.14 & 360 & 25.7 & 2.31 \\
\hline 9 & A0A094ZYF3 & $\begin{array}{c}\text { Putative } \\
\text { aminopeptidase } \\
\text { W07G4.4 }\end{array}$ & 57.6 & 7.55 & 169 & 25.3 & 2.16 \\
\hline 10 & P43157 & Cathepsin B & 38.7 & 7.14 & 522 & 30.4 & 2.33 \\
\hline 11 & A0A095B296 & $\begin{array}{l}\text { Cathepsin B- } \\
\text { like cysteine } \\
\text { proteinase }\end{array}$ & 38.6 & 7.51 & 43 & 38.8 & 2.05 \\
\hline
\end{tabular}


Table 1. Cont

\begin{tabular}{|c|c|c|c|c|c|c|c|}
\hline No. & $\begin{array}{c}\text { Accession No. } \\
\text { Uniprot }\end{array}$ & Protein Name & MW & pI & $\begin{array}{c}\text { Protein } \\
\text { Score }\end{array}$ & $\begin{array}{l}\text { Sequence } \\
\text { Coverage }\end{array}$ & $\begin{array}{c}\text { Average } \\
\text { Fold-Change }\end{array}$ \\
\hline \multicolumn{8}{|c|}{ Antioxidant } \\
\hline 12 & Q26513 & $\begin{array}{l}\text { Glutathione-S- } \\
\text { transferase }\end{array}$ & 23.8 & 6.72 & 76 & 19.4 & -1 \\
\hline \multicolumn{8}{|c|}{ Transcription and translation } \\
\hline 13 & C1LWP5 & $\begin{array}{c}\text { Eukaryotic translation } \\
\text { elongation factor } 1 \\
\text { alpha } 2\end{array}$ & 25.7 & 7.67 & 149 & 36.5 & 3.69 \\
\hline \multicolumn{8}{|c|}{ Immune system } \\
\hline 14 & C1L7Y4 & $\begin{array}{c}\text { Annexin A13 } \\
\text { (Annexin XIII) }\end{array}$ & 39.5 & 5.1 & 242 & 24.9 & 2.48 \\
\hline 15 & Q86DV3 & Annexin & 36.7 & 6.13 & 225 & 36.4 & 3.05 \\
\hline 16 & C1LKB8 & $\begin{array}{l}\text { Prohibitin-2 (B-cell } \\
\text { receptor-associated } \\
\text { protein BAP37) }\end{array}$ & 28.8 & 9.72 & 226 & 38.5 & 3.29 \\
\hline \multicolumn{8}{|c|}{ Antigen } \\
\hline 17 & & 55kD antigen & 45.6 & 4.59 & 40 & 20.2 & -1 \\
\hline \multicolumn{8}{|c|}{ Unknown } \\
\hline 18 & Q5DE25 & SJCHGC06488 protein & 30.2 & 5.54 & 232 & 25.9 & 3.54 \\
\hline 19 & Q5DGY1 & Unknown & 38.7 & 7.86 & 123 & 21.3 & 3.22 \\
\hline 20 & Q5DCK2 & SJCHGC06304 protein & 60.2 & 7.59 & 46 & 11.6 & 2.4 \\
\hline
\end{tabular}

Table 2. Top 20 S. mekongi proteins downregulated after $40 \mu \mathrm{g} / \mathrm{mL}-\mathrm{PZQ}$ treatment.

\begin{tabular}{|c|c|c|c|c|c|c|c|}
\hline No. & $\begin{array}{l}\text { Accession } \\
\text { No.Uniprot }\end{array}$ & Protein Name & MW & pI & $\begin{array}{l}\text { Protein } \\
\text { Score }\end{array}$ & $\begin{array}{l}\text { Sequence } \\
\text { Coverage }\end{array}$ & $\begin{array}{c}\text { Average } \\
\text { Fold-Change }\end{array}$ \\
\hline \multicolumn{8}{|c|}{ Structural protein } \\
\hline 1 & G4VD36 & Tropomyosin, partial & 32.9 & 4.62 & 610 & 63.7 & $0^{1}$ \\
\hline 2 & Q02456 & Myosin heavy chain & 222.2 & 5.55 & 1003 & 27.8 & $0^{1}$ \\
\hline 3 & G4M0G1 & $\begin{array}{l}\text { Myosin heavy chain, } \\
\text { putative }\end{array}$ & 182.4 & 5.6 & 873 & 28.2 & -2.0 \\
\hline \multicolumn{8}{|c|}{ Energy } \\
\hline 4 & B2LXU1 & Enolase & 46.7 & 6.77 & 130 & 24.7 & -3.12 \\
\hline 5 & C1LFP4 & $\begin{array}{l}\text { Putative aldehyde } \\
\text { dehydrogenase } \\
\text { 1B1 precursor }\end{array}$ & 53.5 & 6.06 & 379 & 28.9 & -4.0 \\
\hline 6 & G4LWI3 & $\begin{array}{c}\text { Aldehyde } \\
\text { dehydrogenase, putative }\end{array}$ & 53.7 & 5.76 & 113 & 19.8 & -2.86 \\
\hline 7 & B2LXU3 & $\begin{array}{l}\text { Glyceraldehyde } \\
\text { 3-phosphate } \\
\text { dehydrogenase }\end{array}$ & 36.5 & 7.68 & 152 & 33.4 & -2.63 \\
\hline 8 & C7TRL1 & $\begin{array}{l}\text { Glyceraldehyde } \\
\text { 3-phosphate } \\
\text { dehydrogenase }\end{array}$ & 36.5 & 8.4 & 340 & 33.7 & -2.63 \\
\hline 9 & G4M130 & $\begin{array}{l}\text { Sm14 fatty acid-binding } \\
\text { protein delta E3 variant }\end{array}$ & 10.9 & 8.82 & 85 & 42.9 & $0^{1}$ \\
\hline
\end{tabular}


Table 2. Cont.

\begin{tabular}{|c|c|c|c|c|c|c|c|}
\hline No. & $\begin{array}{l}\text { Accession } \\
\text { No.Uniprot }\end{array}$ & Protein Name & MW & $\mathrm{pI}$ & $\begin{array}{c}\text { Protein } \\
\text { Score }\end{array}$ & $\begin{array}{l}\text { Sequence } \\
\text { Coverage }\end{array}$ & $\begin{array}{c}\text { Average } \\
\text { Fold-Change }\end{array}$ \\
\hline \multicolumn{8}{|c|}{ Stress response } \\
\hline 10 & G4VJ99 & $\begin{array}{l}\text { Putative heat } \\
\text { shock protein }\end{array}$ & 80.7 & 5.91 & 321 & 12.8 & -2.27 \\
\hline \multicolumn{8}{|c|}{ Signaling } \\
\hline 11 & A0A095B084 & Pyruvate kinase PKM & 62 & 6.63 & 136 & 19.3 & -2.38 \\
\hline 12 & C1LEA0 & $\begin{array}{l}\text { TNF receptor-associated } \\
\text { protein } 1\end{array}$ & 80.2 & 6.24 & 321 & 9.8 & -2.27 \\
\hline 13 & C1LFZ8 & Arginine kinase & 80.1 & 8.46 & 56 & 12.8 & -2.27 \\
\hline 14 & A0A095ASB2 & $\begin{array}{c}\text { Inositol } \\
\text { hexakisphosphate and } \\
\text { diphosphoinositol- } \\
\text { pentakisphosphate } \\
\text { kinase 2 }\end{array}$ & 178 & 8.23 & 34 & 8.3 & -2.0 \\
\hline \multicolumn{8}{|c|}{ Unknown } \\
\hline 15 & Q5DAM7 & SJCHGC06305 protein & 61.1 & 6.48 & 278 & 28 & -3.33 \\
\hline 16 & B3GUT7 & Unknown & 16 & 6.9 & 33 & 18.2 & $0^{1}$ \\
\hline 17 & Q5DBJ9 & Unknown & 38.8 & 8.44 & 69 & 22.2 & -2.0 \\
\hline 18 & Q5C296 & $\begin{array}{l}\text { SJCHGC01885 protein, } \\
\text { partial }\end{array}$ & 111.8 & 5.26 & 924 & 37.3 & -2.04 \\
\hline 19 & Q5DEG6 & SJCHGC00214 protein & 53.4 & 8.56 & 306 & 25.1 & -2.22 \\
\hline 20 & Q5DGD4 & SJCHGC06677 protein & 90.6 & 5.08 & 61 & 12.5 & -2.38 \\
\hline
\end{tabular}

\subsection{Effects of PZQ on S. mekongi Phosphorylation and Phosphoprotein Abundance}

Levels of phosphorylation in PZQ-treated S. mekongi was examined by immunogold labeling and visualized by transmission electron microscope (TEM) and compared with untreated parasites. Anti-phosphoserine was used to determine phosphorylation levels and tissue localization in the parasites. In Schistosoma parasite, the main phosphorylated residues are serine (67.8\%), threonine $(20.1 \%)$ and tyrosine (12.1\%) [31]. Phosphorylation of tegument, muscle and internal cells of the worms were markedly reduced after PZQ treatment, as indicated by the black spots in Figure 3. The reduction of phosphorylation could be one of the effects of PZQ treatment. To explore the mechanism of action of PZQ on parasite phosphorylation, phosphoprotein abundance of untreated and PZQ-treated S. mekongi were profiled using MS-based phosphoproteomics.

A total of 448 phosphoproteins of S. mekongi were identified using TALON PMAC Magnetic Phospho Enrichment Kit and MS. Among these, 43 phosphoproteins differed after PZQ exposure. Twenty-eight phosphoproteins were upregulated and 15 were downregulated after PZQ treatment. MS-identified phosphopeptides of up- and downregulated phosphoproteins were 124 and 44 peptides, respectively (Tables 3 and 4). Phosphoproteins involved in structure, energy, protease, antigen, transcription and translation, immune system, stress response, transporters and antioxidants were upregulated. An unknown protein, SJCHGC01909, was the most upregulated phosphoprotein after PZQ treatment (6.13-fold increase). Some phosphoproteins involved in structure, energy, antigen, scaffold, antioxidant, transcription and translation, stress response and signaling were also downregulated. Energy metabolism protein aldolase was the most downregulated phosphoprotein (2.38-fold decrease). Gene ontology classification of differential phosphoproteins after PZQ exposure using the biologic process term showed that differential phosphoproteins mostly affected protein folding $(19 \%)$, cell redox homeostasis $(13 \%)$, cellular oxidant detoxification $(13 \%)$ and microtubule-based process (13\%) (Figure 4A). Furthermore, the molecular function term classification revealed that most 
altered phosphoproteins related to ATP binding (34\%) and protein binding (20\%) (Figure 4B). For the cellular component term, most differential phosphoproteins were integral membrane (23\%), myofibril $(18 \%)$ and myosin filament (18\%) components (Figure 4C).

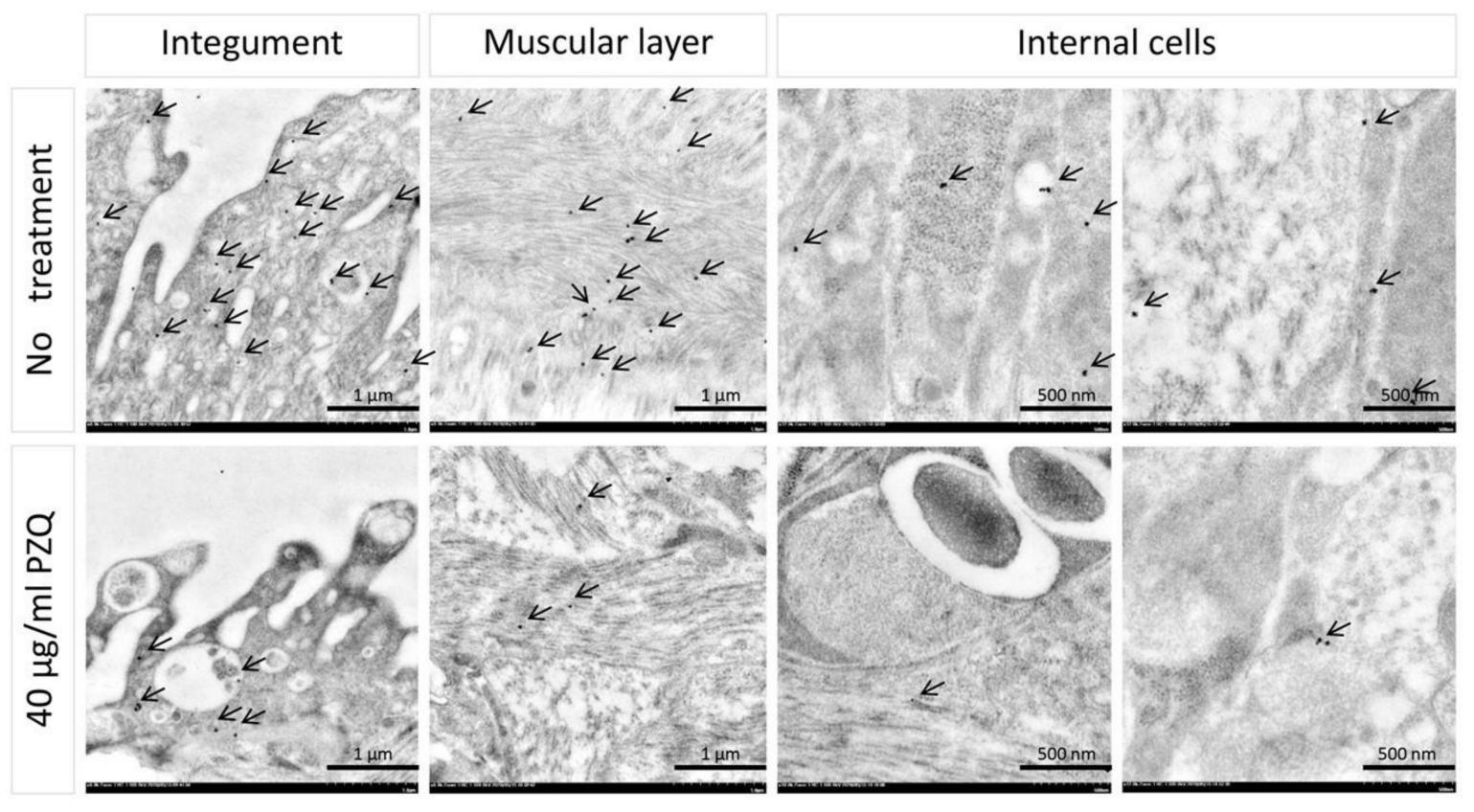

Figure 3. Level of phosphorylation in tegument, muscle layer and internal cells decreased after PZQ treatment. Phosphorylation on untreated and PZQ-treated S. mekongi were tagged by anti-phosphoserine antibody. Immune-gold labeling and electron microscope were used to visualize parasite phosphorylation. Phosphorylation is indicated by black spots with arrows. The numbers of spots are markedly reduced in all organs after PZQ treatment.

Table 3. Increased abundance of S. mekongi phosphoproteins after $40 \mu \mathrm{g} / \mathrm{mL}-\mathrm{PZQ}$ treatment.

\begin{tabular}{|c|c|c|c|c|c|}
\hline \multirow{2}{*}{ No. } & \multirow{2}{*}{$\begin{array}{l}\text { Accession } \\
\text { No. Uniprot }\end{array}$} & \multirow{2}{*}{ Protein Name } & \multicolumn{2}{|c|}{ Phosphorylation Site } & \multirow{2}{*}{$\begin{array}{c}\text { Average } \\
\text { Fold-Change }\end{array}$} \\
\hline & & & Peptide Sequence & Number & \\
\hline \multicolumn{6}{|c|}{ Structural protein } \\
\hline \multirow{16}{*}{1} & \multirow{16}{*}{ A5A6F8 } & \multirow{16}{*}{ Paramyosin } & QASEDRATR & 1 (ST) & \multirow{16}{*}{2} \\
\hline & & & GVSPSTTRLESR & $1(\mathrm{ST})$ & \\
\hline & & & MMNHDTESHVKISR & $1(\mathrm{ST})$ & \\
\hline & & & TIYRGVSPSTTR & $5(\mathrm{ST}), 1(\mathrm{Y})$ & \\
\hline & & & GMRATSMM & $2(\mathrm{ST})$ & \\
\hline & & & ADMAERTVTVR & $1(\mathrm{ST})$ & \\
\hline & & & AKSSLESQVDDLK & $1(\mathrm{ST})$ & \\
\hline & & & LKAVSLEK & 1 (ST) & \\
\hline & & & GVSPSTTR & $3(\mathrm{ST})$ & \\
\hline & & & QLTELNNAK & $1(\mathrm{ST})$ & \\
\hline & & & LEGLDSQLNR & $1(\mathrm{ST})$ & \\
\hline & & & LDEAGGSTTQTQELLKR & $3(\mathrm{ST})$ & \\
\hline & & & ISRTIYR & $2(\mathrm{ST})$ & \\
\hline & & & ATRLNNEVLR & $1(\mathrm{ST})$ & \\
\hline & & & ELSVTSNRGMR & $2(\mathrm{ST})$ & \\
\hline & & & KHAETELEEAQSR & $1(\mathrm{ST})$ & \\
\hline
\end{tabular}


Table 3. Cont.

\begin{tabular}{|c|c|c|c|c|c|}
\hline \multirow{2}{*}{ No. } & \multirow{2}{*}{$\begin{array}{l}\text { Accession } \\
\text { No. Uniprot }\end{array}$} & \multirow{2}{*}{ Protein Name } & \multicolumn{2}{|l|}{ Phosphorylation Site } & \multirow{2}{*}{$\begin{array}{c}\text { Average } \\
\text { Fold-Change }\end{array}$} \\
\hline & & & Peptide Sequence & Number & \\
\hline \multirow{13}{*}{2} & \multirow{13}{*}{ Q05870 } & \multirow{13}{*}{ Paramyosin } & GVSPSTTRLESR & $1(\mathrm{ST})$ & \multirow{13}{*}{2.47} \\
\hline & & & MMNHDTESHVKISR & $1(\mathrm{ST})$ & \\
\hline & & & TIYRGVSPSTTR & $5(\mathrm{ST}), 1(\mathrm{Y})$ & \\
\hline & & & AERHAADLSYQVDALSER & $1(\mathrm{ST})$ & \\
\hline & & & GMRATSMM & $1(\mathrm{ST})$ & \\
\hline & & & ADMAERTVTVR & $1(\mathrm{ST})$ & \\
\hline & & & AKSSLESQVDDLK & $1(\mathrm{ST})$ & \\
\hline & & & VSELTIQVNTLSNDK & $1(\mathrm{ST})$ & \\
\hline & & & LKAVSLEK & $1(\mathrm{ST})$ & \\
\hline & & & GVSPSTTR & $3(\mathrm{ST})$ & \\
\hline & & & QLTELNNAK & $1(\mathrm{ST})$ & \\
\hline & & & LEGLDSQLNR & $1(\mathrm{ST})$ & \\
\hline & & & LDEAGGSTTQTQELLKR & $3(\mathrm{ST})$ & \\
\hline 3 & Q26507 & Paramyosin, partial & ATRLNNEVLR & $1(\mathrm{ST})$ & -1 \\
\hline \multirow{5}{*}{4} & \multirow{5}{*}{ A0A095BХK4 } & \multirow{5}{*}{ Actin-1 } & GTAASSSALEK & $4(\mathrm{ST})$ & \multirow{5}{*}{-1} \\
\hline & & & MQKEISALAPSTMK & $1(\mathrm{ST})$ & \\
\hline & & & QEYDESGPSIVHRK & $1(\mathrm{ST}), 1(\mathrm{Y})$ & \\
\hline & & & EISALAPSTMK & $1(\mathrm{ST})$ & \\
\hline & & & DLYSNTVLSGGSTMYPGIADR & $1(\mathrm{ST}), 1(\mathrm{Y})$ & \\
\hline \multirow{2}{*}{5} & \multirow{2}{*}{ A0A094ZID2 } & \multirow{2}{*}{ Actin-1 } & EICNLAPTTMKIK & $2(\mathrm{ST})$ & \multirow{2}{*}{-1} \\
\hline & & & KDLYSNIVLSGGSTMFPGISDR & $2(\mathrm{ST})$ & \\
\hline \multirow{7}{*}{6} & \multirow{7}{*}{ G4VBJ0 } & \multicolumn{3}{|c|}{ Energy } & \\
\hline & & & RIQEAGTEVVEAK & $1(\mathrm{ST})$ & \multirow{6}{*}{2.25} \\
\hline & & & AGAGSATLSMAYAGVR & $2(\mathrm{ST}), 1(\mathrm{Y})$ & \\
\hline & & Putative malate & FGISFRSFLTSSK & $5(\mathrm{ST})$ & \\
\hline & & dehydrogenase & LFGVTTLDVVR & $1(\mathrm{ST})$ & \\
\hline & & & SFLTSSKHSPK & $4(\mathrm{ST})$ & \\
\hline & & & AMICIITNPVNSTVPIAAEILK & $2(\mathrm{ST})$ & \\
\hline & & & FDESTVQNDITHYPFSVVNKK & $3(\mathrm{ST}), 1(\mathrm{Y})$ & \\
\hline 7 & A0A095CGL8 & $78 \mathrm{kDa}$ glucose-regulated & DIKTNK & $1(\mathrm{ST})$ & -1 \\
\hline & & & EFAESYLGK & $1(\mathrm{ST})$ & \\
\hline & & & FDESTVQNDITHYPFSVVNKK & $3(\mathrm{ST}), 1(\mathrm{Y})$ & \\
\hline & & & Protease & & \\
\hline & & & DIMMYGPVEAAFDVYEDFLNYK & $1(\mathrm{Y})$ & \\
\hline & & & IAVYIVSLFTFLEAHVTTR & $3(\mathrm{ST})$ & \\
\hline & & & MATLGTGMR & $2(\mathrm{ST})$ & \\
\hline 8 & P43157 & Cathepsin B & AEISMLEGAVLDIRYGVSR & $1(\mathrm{ST}), 1(\mathrm{Y})$ & -1 \\
\hline & & & IDDEINTLMTGALENPNEEITATMDK & $3(\mathrm{ST})$ & \\
\hline & & & YGVSRIAYSK & $2(\mathrm{ST}), 1(\mathrm{Y})$ & \\
\hline & & & MATLGTGMRCLK & $1(\mathrm{ST})$ & \\
\hline & & & Antigen & & \\
\hline & & & MATTEYRLSLMEQFIR & $1(\mathrm{ST})$ & \\
\hline 9 & Q03528 & $\begin{array}{l}22.6 \mathrm{kd} \text { tegumental } \\
\text { associated antigen }\end{array}$ & ATTEYR & $1(\mathrm{ST}), 1(\mathrm{Y})$ & -1 \\
\hline & & & ATTEYRLSLMEQFIR & $1(\mathrm{ST})$ & \\
\hline 10 & P08418 & $70,000 \mathrm{~mol} w \mathrm{t}$ antigen/hsp70 & TTPSYVAFTDSER & $3(\mathrm{ST}), 1(\mathrm{Y})$ & 1 \\
\hline 10 & P08418 & homologue (619 AA), partial & MFSPEEISSMVLTKMK & $1(\mathrm{ST})$ & -1 \\
\hline 11 & C1I 7Y4 & Annexin A13 (Annexin XIII) & IIGILGYR & $1(\mathrm{Y})$ & 1 \\
\hline 11 & CIL/Y4 & 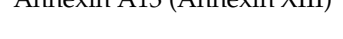 & MLLTDTDKMNAR & $1(\mathrm{ST})$ & \\
\hline
\end{tabular}


Table 3. Cont.

\begin{tabular}{|c|c|c|c|c|c|}
\hline \multirow{2}{*}{ No. } & \multirow{2}{*}{$\begin{array}{l}\text { Accession } \\
\text { No. Uniprot }\end{array}$} & \multirow{2}{*}{ Protein Name } & \multicolumn{2}{|l|}{ Phosphorylation Site } & \multirow{2}{*}{$\begin{array}{c}\text { Average } \\
\text { Fold-Change }\end{array}$} \\
\hline & & & Peptide Sequence & Number & \\
\hline \multicolumn{6}{|c|}{ Transcription and translation } \\
\hline \multirow{5}{*}{12} & \multirow{5}{*}{ G4VAD2 } & \multirow{5}{*}{$\begin{array}{l}\text { Putative elongation factor } \\
\text { 1-alpha (EF-1-alpha) }\end{array}$} & TEDNPKCIK & 1 (ST) & \multirow{5}{*}{-1} \\
\hline & & & ESGEMGKGSFK & $1(\mathrm{ST})$ & \\
\hline & & & KESAAK & $1(\mathrm{ST})$ & \\
\hline & & & MTDKPLR & $1(\mathrm{ST})$ & \\
\hline & & & MDCTEPPFSEDR & $1(\mathrm{ST})$ & \\
\hline \multirow{2}{*}{13} & \multirow{2}{*}{ A0A094ZN49 } & \multirow{2}{*}{$\begin{array}{l}\text { S phase cyclin A-associated } \\
\text { protein in the } \\
\text { endoplasmic reticulum }\end{array}$} & TASNTRSGSLISTNSR & $2(\mathrm{ST})$ & \multirow{2}{*}{-1} \\
\hline & & & SGSLISTNSR & $2(\mathrm{ST})$ & \\
\hline \multirow{10}{*}{14} & \multirow{10}{*}{ G4M170 } & \multirow{10}{*}{$\begin{array}{l}\text { Meiotic checkpoint regulator } \\
\text { cut } 4 \text {, putative }\end{array}$} & GISSSSR & $2(\mathrm{ST})$ & \multirow{10}{*}{-1} \\
\hline & & & HNSINMTTLR & 1 (ST) & \\
\hline & & & GASFSSSTFR & $4(\mathrm{ST})$ & \\
\hline & & & CVDSLDSNKFLR & $1(\mathrm{ST})$ & \\
\hline & & & YTGNIVSSECQNNVGHIFQSSKR & $1(\mathrm{ST})$ & \\
\hline & & & GMLTFGILTGSK & $1(\mathrm{ST})$ & \\
\hline & & & SSGSGLFYECSRK & $3(\mathrm{ST}), 1(\mathrm{Y})$ & \\
\hline & & & WYIISNAPGTKSSYK & $1(\mathrm{ST})$ & \\
\hline & & & CPDQTFTDSLYHAYGR & $2(\mathrm{ST})$ & \\
\hline & & & VWASVIGRGMLTFGILTGSK & $1(\mathrm{ST})$ & \\
\hline \multirow{8}{*}{15} & & & \multicolumn{2}{|l|}{ Immune system } & \\
\hline & \multirow{7}{*}{ G4VL68 } & \multirow{7}{*}{ Putative annexin } & STSRLVSR & $2(\mathrm{ST})$ & \multirow{7}{*}{-1} \\
\hline & & & CEVDMNTLKSMYR & $1(\mathrm{ST}), 1(\mathrm{Y})$ & \\
\hline & & & GDSDTFIK & $2(\mathrm{ST})$ & \\
\hline & & & EDTSGDFR & $2(\mathrm{ST})$ & \\
\hline & & & CEVDMNTLK & $1(\mathrm{ST})$ & \\
\hline & & & GLSTDEETITK & $2(\mathrm{ST})$ & \\
\hline & & & NVVITVPAYFNDSQR & $1(\mathrm{ST})$ & \\
\hline & & & tress response & & \\
\hline 10 & 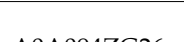 & Heat shock $70 \mathrm{kDa}$ & RTLSSST & $4(\mathrm{ST})$ & 1 \\
\hline 16 & AUAU94ZG 26 & protein-like protein, partial & LFSAEEISSMVLTK & $1(\mathrm{ST})$ & -1 \\
\hline & & & EEMEASNSEYEKEK & $1(\mathrm{ST}), 1(\mathrm{Y})$ & \\
\hline 17 & Q8MXA4 & $\begin{array}{l}\text { Heat shock protein HSP60, } \\
\text { partial }\end{array}$ & DMAVGTGGIVFGDEADMYK & $1(\mathrm{ST}), 1(\mathrm{Y})$ & -1 \\
\hline & & & SAMLVGVDILADADAVTMGPKGR & $1(\mathrm{ST})$ & \\
\hline 18 & O45038 & HSP70 & MKSSAESYLGK & $2(\mathrm{ST})$ & -1 \\
\hline 19 & C4IWIT & Heat shock protein HSP60, & EEMEASNSEYEKEK & $1(\mathrm{ST}), 1(\mathrm{Y})$ & 1 \\
\hline & & putative & VGNDGTITVKMK & $1(\mathrm{ST})$ & -1 \\
\hline & & & Transporter & & \\
\hline 20 & A0A094ZO18 & Putative sodium-coupled & SFQPTLSNMR & $3(\mathrm{ST})$ & 1 \\
\hline & & transporter 10 & NPPEPIDLTKIQSQMNVNNK & $1(\mathrm{ST})$ & \\
\hline & & & Antioxidant & & \\
\hline 21 & A0A095A0V3 & Peroxiredoxin-2 & & & -1 \\
\hline & & & GIPGNSSMASK & $2(\mathrm{ST})$ & \\
\hline 22 & & Glutathione S-transferase & AEISMLEGAVLDIRYGVSR & $1(\mathrm{ST}), 1(\mathrm{Y})$ & -1 \\
\hline & & & YGVSRIAYSK & $2(\mathrm{ST}), 1(\mathrm{Y})$ & \\
\hline 23 & G4LXF8 & $\begin{array}{l}26 \mathrm{Kd} \\
\text { glutathione-S-transferase, } \\
\text { Sm26, putative }\end{array}$ & & & -1 \\
\hline
\end{tabular}


Table 3. Cont.

\begin{tabular}{|c|c|c|c|c|c|}
\hline \multirow{2}{*}{ No. } & \multirow{2}{*}{$\begin{array}{l}\text { Accession } \\
\text { No. Uniprot }\end{array}$} & \multirow{2}{*}{ Protein Name } & \multicolumn{2}{|l|}{ Phosphorylation Site } & \multirow{2}{*}{$\begin{array}{l}\text { Average } \\
\text { Fold-Change }\end{array}$} \\
\hline & & & Peptide Sequence & Number & \\
\hline \multicolumn{6}{|c|}{ Unknown } \\
\hline \multirow{10}{*}{24} & \multirow{10}{*}{ Q5DBM4 } & \multirow{10}{*}{ SJCHGC01909 protein } & MNHDSESHVK & $2(\mathrm{ST})$ & \multirow{10}{*}{6.13} \\
\hline & & & GVSPSTTRLESR & $1(\mathrm{ST})$ & \\
\hline & & & TIYRGVSPSTTR & $5(\mathrm{ST}), 1(\mathrm{Y})$ & \\
\hline & & & AERHAADLSYQVDALSER & $1(\mathrm{ST})$ & \\
\hline & & & GVSPSTTR & $3(\mathrm{ST})$ & \\
\hline & & & QLTELNNAK & $1(\mathrm{ST})$ & \\
\hline & & & LEGLDSQLNR & 1 (ST) & \\
\hline & & & MNHDSESHVK & $2(\mathrm{ST})$ & \\
\hline & & & LDEAGGSTTQTQELLKR & $3(\mathrm{ST})$ & \\
\hline & & & ISRTIYR & $2(\mathrm{ST})$ & \\
\hline \multirow{7}{*}{25} & \multirow{7}{*}{ G4VM49 } & \multirow{7}{*}{$\begin{array}{l}\text { Hypothetical protein } \\
\text { Smp_179350 }\end{array}$} & WSSSSSNK & $1(\mathrm{ST})$ & \multirow{7}{*}{-1} \\
\hline & & & FSSTSSTR & $3(\mathrm{ST})$ & \\
\hline & & & SINDNSSIEK & 2 (ST) & \\
\hline & & & TMRSLDSCIVPR & $1(\mathrm{ST})$ & \\
\hline & & & ISGLTPVSTIFTGASNTTSTSTACGAVK & $4(\mathrm{ST})$ & \\
\hline & & & LNTSR & $1(\mathrm{ST})$ & \\
\hline & & & KQHSQSHDNLECSK & $1(\mathrm{ST})$ & \\
\hline 26 & B3GUU7 & Unknown & & & -1 \\
\hline \multirow{3}{*}{27} & \multirow{3}{*}{ Q5DGY9 } & \multirow{3}{*}{ SJCHGC06312 protein } & MAGESGTKTESQSDESTK & $2(\mathrm{ST})$ & \multirow{3}{*}{-1} \\
\hline & & & TESQSDESTK & $1(\mathrm{ST})$ & \\
\hline & & & DSETAESIK & $3(\mathrm{ST})$ & \\
\hline \multirow{6}{*}{28} & \multirow{6}{*}{ G4M072 } & \multirow{6}{*}{$\begin{array}{l}\text { Hypothetical protein } \\
\text { Smp_153120 }\end{array}$} & LSHSGVDDK & $1(\mathrm{ST})$ & \multirow{6}{*}{-1} \\
\hline & & & QCLNLTSYSK & 1 (ST) & \\
\hline & & & TPSSIKVYDLK & $1(\mathrm{ST})$ & \\
\hline & & & SKYGWAPNSLLLGK & $1(Y)$ & \\
\hline & & & MNDVTLSMVCNIR & 1 (ST) & \\
\hline & & & TSASNTVHTIHDITVKR & 4 (ST) & \\
\hline
\end{tabular}

${ }^{1}$ phosphoprotein only identified in PZQ treatment.

Table 4. Decreased abundance of $S$. mekongi phosphoproteins after $40 \mu \mathrm{g} / \mathrm{mL}-\mathrm{PZQ}$ treatment.

\begin{tabular}{|c|c|c|c|c|c|}
\hline \multirow{2}{*}{ No. } & \multirow{2}{*}{$\begin{array}{l}\text { Accession } \\
\text { No. Uniprot }\end{array}$} & \multirow{2}{*}{ Protein Name } & \multicolumn{2}{|l|}{ Phosphorylation Site } & \multirow{2}{*}{$\begin{array}{l}\text { Average } \\
\text { Fold-Change }\end{array}$} \\
\hline & & & Peptide Sequence & Number & \\
\hline \multicolumn{6}{|c|}{ Structural protein } \\
\hline \multirow{4}{*}{1} & \multirow{4}{*}{ G4VLW1 } & \multirow{4}{*}{ Putative actin } & GYSFTTTAER & $2(\mathrm{ST})$ & \multirow{4}{*}{$0^{1}$} \\
\hline & & & DSYVGDEAQSK & $2(\mathrm{ST})$ & \\
\hline & & & GDEDVAALVIDNGSGMCK & $1(\mathrm{ST})$ & \\
\hline & & & YSVWIGGSILASLSTFQQMWISK & $1(\mathrm{ST}), 1(\mathrm{Y})$ & \\
\hline \multirow{3}{*}{2} & \multirow{3}{*}{ G4VD37 } & \multirow{3}{*}{ Putative tropomyosin } & EKAEAEVAAMTR & $1(\mathrm{ST})$ & \multirow{3}{*}{$0^{1}$} \\
\hline & & & EESYEETIRDLTER & $3(\mathrm{ST}), 1(\mathrm{Y})$ & \\
\hline & & & LLEEDLEVSSSRLTETLTK & $2(\mathrm{ST})$ & \\
\hline \multicolumn{6}{|c|}{ Energy } \\
\hline \multirow{3}{*}{3} & \multirow{3}{*}{ C1LV81 } & \multirow{3}{*}{ Aldolase } & HNMVTAGQACK & $1(\mathrm{ST})$ & \multirow{3}{*}{-2.38} \\
\hline & & & TLPTLLAERHIIPGIK & $1(\mathrm{ST})$ & \\
\hline & & & TLPTLLAER & $1(\mathrm{ST})$ & \\
\hline \multicolumn{6}{|c|}{ Antigen } \\
\hline 4 & C1L9U2 & Tegument antigen $(\mathrm{I}(\mathrm{H}) \mathrm{A})$ & EGKVSTLPLVIQIIAATMSK & $2(\mathrm{ST})$ & $0^{1}$ \\
\hline
\end{tabular}


Table 4. Cont.

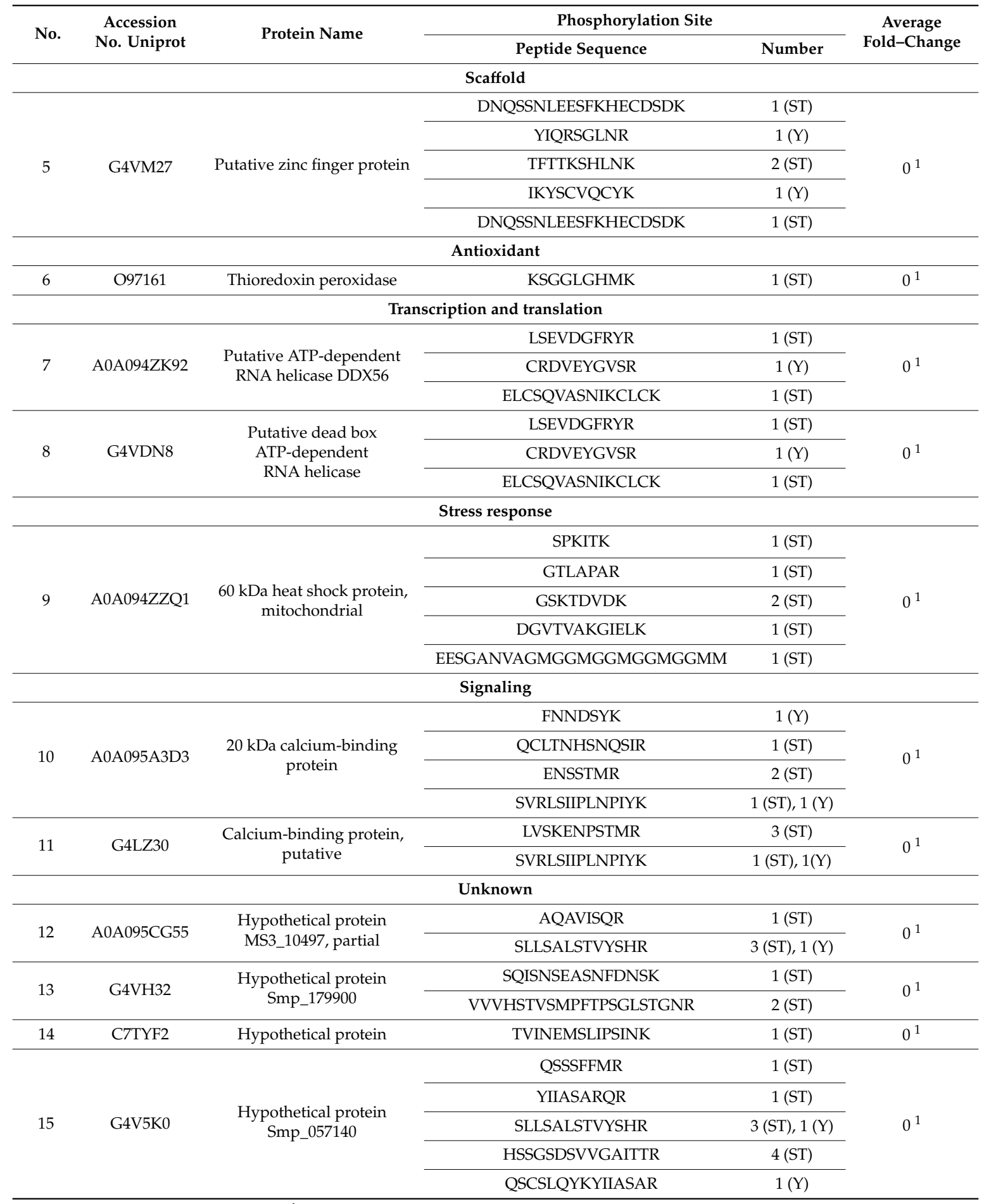

\footnotetext{
${ }^{1}$ phosphoprotein only identified without treatment.
}

The integrated proteomic and phosphoproteomic data revealed that 1348 proteins could be identified. After S. mekongi were exposed to PZQ, a total of 144 proteins were identified by proteomics as showing differential expression and 43 phosphoproteins were altered as identified by phosphoproteomics. However, 138 proteins were found to be altered by proteomics analysis alone. These proteins may indicate the effect of PZQ at the protein expression level. Likewise, 37 proteins were found to be altered by phosphoproteomic analysis alone, which could reflect the effect of PZQ at the phosphorylation level. Only six proteins-paramyosin, cathepsin B, annexin, glutathione S-transferase, 
aldolase and heat shock protein—showed the alterations by both proteomic and phosphoproteomic approaches (Figure 5).

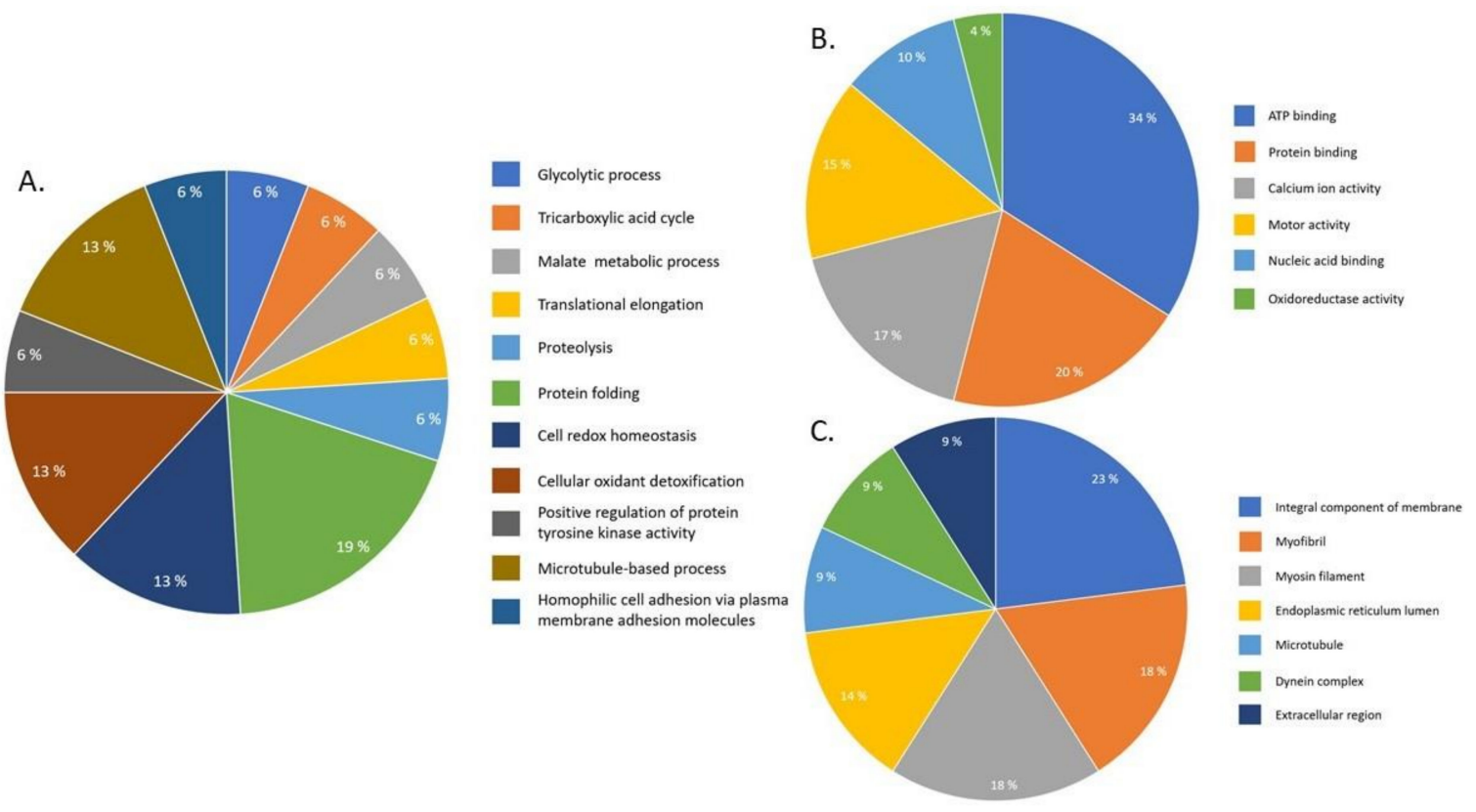

Figure 4. Gene ontology classification of S. mekongi phosphoproteomic data after PZQ treatment. The differential phosphoproteins after PZQ exposure were classified according to their gene ontology using Blast2Go. Three terms of gene ontologies including (A) biologic process, (B) molecular function and $(\mathbf{C})$ cellular component are presented.

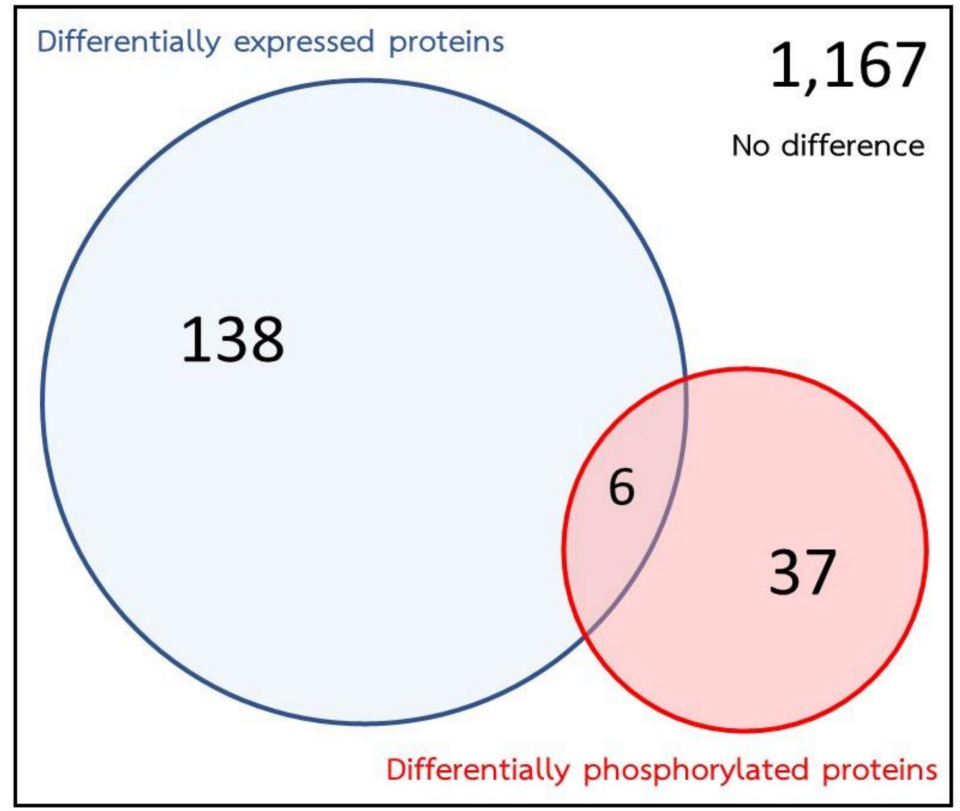

Figure 5. Distribution of proteomic and phosphoproteomic data. Identification of proteins by mass spectrometer showed the total of 1167 proteins. Expression levels of 138 proteins changed after PZQ treatment without altering their phosphorylation. Thirty-seven phosphoproteins changed without changing their expression. Six proteins were altered both of their expression and phosphorylation. 


\subsection{Pathway Analysis}

To fully understand the anthelmintic mechanisms of PZQ, the integral proteomic and phosphoproteomic data were further investigated by KAAS bioinformatic software. The result suggested that protein processing in the endoplasmic reticulum (ER) (pathway ID: 04,141) was the main enriched pathway in this study. As shown in Figure 6, differentiations of 10 proteins (green boxes) and two phosphoproteins (red borders) were detected in this pathway after treatment. Furthermore, most differential proteins and phosphoproteins affected by PZQ were mapped to protein misfolding and ER-associated degradation (ERAD). These two processes control the quality of newly synthesized proteins and degrade misfolded proteins. Findings of KAAS analysis correlated with the gene ontology classification, which demonstrated that protein folding, unfolding protein binding, proteolysis and endopeptidase activity were altered by PZQ treatment (Figures 2 and 4). Therefore, alteration of protein processing in the ER, especially on the ERAD pathway, may be a possible mechanism of action of PZQ in S. mekongi. The integrated proteomic and phosphoproteomic data not only provided a novel PZQ mechanism, but also supported the putative PZQ mechanisms on schistosome including calcium homeostasis, tegument damage and induction of oxidative stress. There were 9, 10 and 28 proteins with altered regulation in calcium homeostasis, worm antigens and oxidative stress, respectively (Table 5).

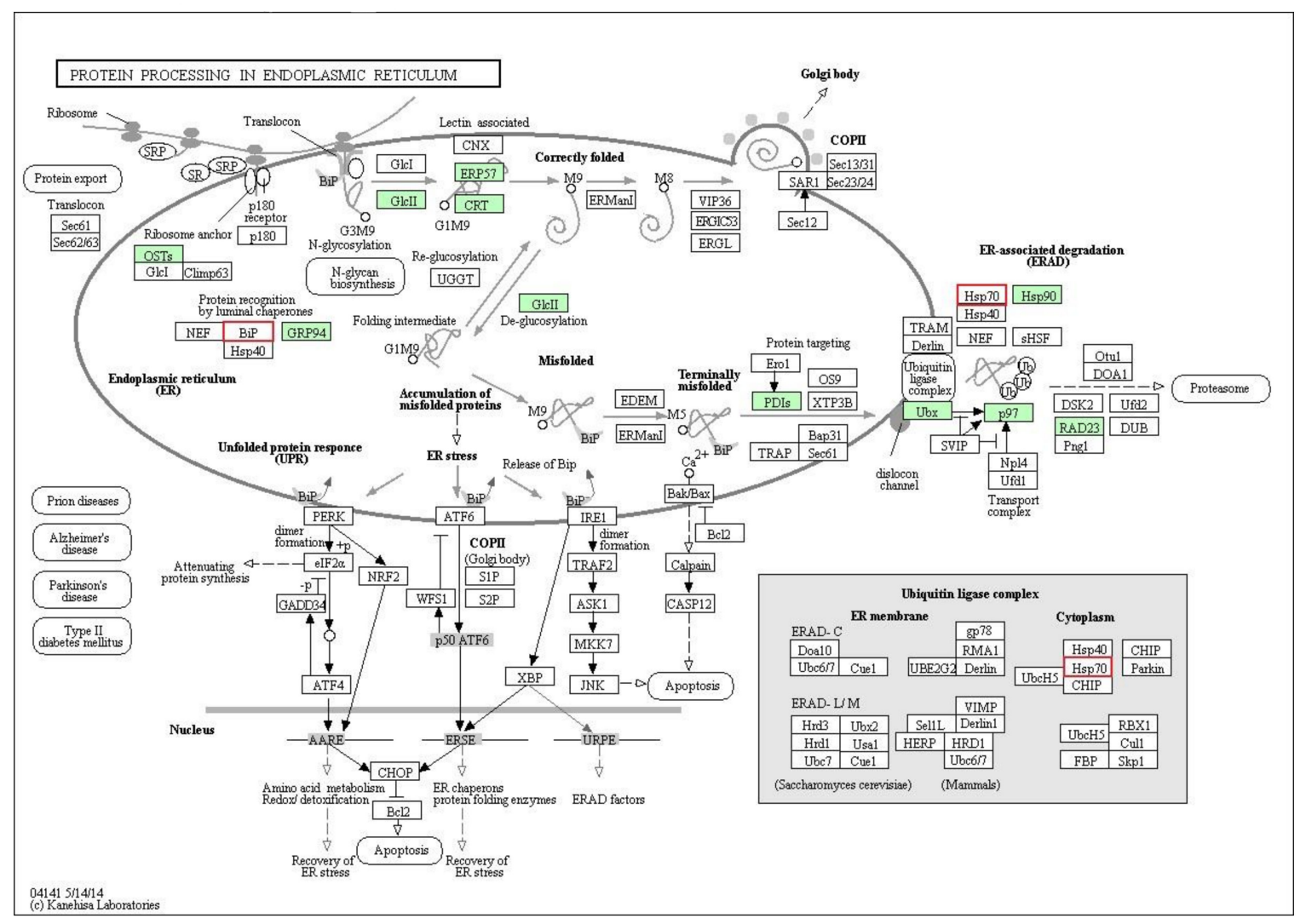

Figure 6. Differentially expressed and phosphorylated proteins after PZQ treatment by the protein processing endoplasmic reticulum (ER) pathway. Differential proteins and phosphoproteins were analyzed for the potential pathways which were affected by PZQ using KEGG Automatic Annotation Server (KAAS) bioinformatic tool. Protein processing ER pathway was highlighted as the major pathway. The differential proteins and phosphorylated are indicated by green boxes and red borders, respectively. 
Table 5. Proteomic and phosphoproteomic analysis of proteins involved in calcium binding, worm antigen oxidative stress and protein folding and proteolysis pathway.

\begin{tabular}{|c|c|c|c|c|}
\hline \multirow{2}{*}{ No. } & \multirow{2}{*}{$\begin{array}{l}\text { Accession } \\
\text { No. Uniprot }\end{array}$} & \multirow{2}{*}{ Protein Name } & \multicolumn{2}{|c|}{ Status } \\
\hline & & & Expression & Phosphorylation \\
\hline \multicolumn{5}{|c|}{ Proteins involving with calcium binding } \\
\hline 1 & C1L7Y4 & Annexin A13 (Annexin XIII) & $\mathrm{Up}$ & - \\
\hline 2 & C1LNX4 & $\begin{array}{l}\text { Voltage-dependent anion-selective channel } \\
\text { protein } 2\end{array}$ & Down & - \\
\hline 3 & G4M1U8 & $\begin{array}{l}\text { Voltage-dependent anion-selective channel, } \\
\text { putative }\end{array}$ & Down & - \\
\hline 4 & G4VL68 & Putative annexin & Down & Up \\
\hline 5 & Q03528 & 22.6kd tegumental associated antigen & - & Up \\
\hline 6 & G4LZ30 & Calcium-binding protein, putative & - & Down \\
\hline 7 & A0A095A3D3 & $20 \mathrm{kDa}$ calcium-binding protein & - & Down \\
\hline 8 & C1L9U2 & Tegument antigen $(\mathrm{I}(\mathrm{H}) \mathrm{A})$ & - & Down \\
\hline 9 & G4VH32 & Hypothetical protein Smp_179900 & - & Down \\
\hline \multicolumn{5}{|c|}{ Proteins involving with worm antigens } \\
\hline 10 & Q26595 & Alpha tubulin & Up & - \\
\hline 11 & Q86DV9 & $\begin{array}{l}\text { Similar to GenBank Accession Number Z29075 } \\
\text { myophilin antigen in Echinococcus granulosus }\end{array}$ & Up & - \\
\hline 12 & A0A094ZPJ2 & Putative citrate synthase 2, mitochondrial & Up & - \\
\hline 13 & & $55 \mathrm{kD}$ antigen & Up & - \\
\hline 14 & Q06814 & Antigen & Down & - \\
\hline 15 & Q5D9C5 & SJCHGC09453 protein & Down & - \\
\hline 16 & P08418 & $\begin{array}{l}\text { 70,000 mol wt antigen/hsp70 homolog (619 } \\
\text { AA), partial }\end{array}$ & - & Up \\
\hline 17 & Q03528 & 22.6kd tegumental associated antigen & - & Up \\
\hline 18 & C1L9U2 & Tegument antigen $(\mathrm{I}(\mathrm{H}) \mathrm{A})$ & - & Down \\
\hline 19 & A0A094ZZQ1 & $60 \mathrm{kDa}$ heat shock protein, mitochondrial & - & Down \\
\hline \multicolumn{5}{|c|}{ Proteins involving with oxidative stress } \\
\hline 20 & C1LV40 & Tryparedoxin peroxidase & Up & - \\
\hline 21 & Q26513 & Glutathione-S-transferase & Up & - \\
\hline 22 & A0A094ZC89 & L-lactate dehydrogenase A chain & Up & - \\
\hline 23 & P37227 & Malate dehydrogenase, partial & Up & - \\
\hline 24 & C1LD38 & Glyceraldehyde 3-phosphate dehydrogenase & Up & - \\
\hline 25 & A0A095AJN4 & Enolase & Up & - \\
\hline 26 & Q7Z1I3 & Lactate dehydrogenase-like protein & Up & - \\
\hline 27 & A0A094ZPJ2 & Putative citrate synthase 2, mitochondrial & Up & - \\
\hline 28 & Q8WT66 & Phosphoglycerate mutase & Up & - \\
\hline 29 & C1LV81 & Aldolase & Up & - \\
\hline 30 & C1LFZ8 & Arginine kinase & Down & - \\
\hline 31 & A0A095B084 & Pyruvate kinase PKM & Down & - \\
\hline 32 & C7TRL1 & Glyceraldehyde 3-phosphate dehydrogenase & Down & - \\
\hline 33 & C1LD30 & Glyceraldehyde 3-phosphate dehydrogenase & Down & - \\
\hline 34 & B2LXU3 & Glyceraldehyde 3-phosphate dehydrogenase & Down & - \\
\hline 35 & B2LXU1 & Enolase & Down & - \\
\hline 36 & C1LFP4 & $\begin{array}{l}\text { Putative aldehyde dehydrogenase 1B1 } \\
\text { precursor }\end{array}$ & Down & - \\
\hline
\end{tabular}


Table 5. Cont.

\begin{tabular}{|c|c|c|c|c|}
\hline \multirow{2}{*}{ No. } & \multirow{2}{*}{$\begin{array}{l}\text { Accession } \\
\text { No. Uniprot }\end{array}$} & \multirow{2}{*}{ Protein Name } & \multicolumn{2}{|c|}{ Status } \\
\hline & & & Expression & Phosphorylation \\
\hline 37 & G4LWI3 & Aldehyde dehydrogenase, putative & Down & - \\
\hline 38 & A0A095A4B6 & Aldehyde dehydrogenase $X$, mitochondrial & Down & - \\
\hline 39 & Q5DAK2 & SJCHGC06828 protein & Down & - \\
\hline 40 & Q5BXP5 & SJCHGC05927 protein, partial & Down & - \\
\hline 41 & Q5DAM7 & SJCHGC06305 protein & Down & - \\
\hline 42 & Q5DFZ8 & SJCHGC00411 protein & Down & - \\
\hline 43 & C1L6T7 & Hypothetical protein & Down & - \\
\hline 44 & G4VBJ0 & Putative malate dehydrogenase & - & $\mathrm{Up}$ \\
\hline 45 & A0A095A0 V3 & Peroxiredoxin-2 & - & Up \\
\hline 46 & G4LXF8 & 26 Kd glutathione-S-transferase, Sm26, putative & - & $\mathrm{Up}$ \\
\hline 47 & O97161 & Thioredoxin peroxidase & - & Down \\
\hline \multicolumn{5}{|c|}{ Proteins involving with protein folding and proteolysis } \\
\hline 48 & P43157 & Cathepsin B & Up & Up \\
\hline 49 & C1L5C5 & Putative aminopeptidase W07G4.4 & Up & - \\
\hline 50 & A0A094ZYF3 & Putative aminopeptidase W07G4.4 & $\mathrm{Up}$ & - \\
\hline 51 & A0A095B296 & Cathepsin B-like cysteine proteinase & Up & - \\
\hline 52 & C1LA34 & Cathepsin B-like cysteine proteinase precursor & Up & - \\
\hline 53 & C1L8N7 & $\begin{array}{l}\text { Putative Lysosomal Pro-X carboxypeptidase } \\
\text { precursor }\end{array}$ & Up & - \\
\hline 54 & G4LYP1 & $\begin{array}{l}\text { Mitochondrial processing peptidase } \\
\text { beta-subunit (M16 family) }\end{array}$ & Up & - \\
\hline 55 & G4VPS5 & $\begin{array}{l}\text { Putative chaperonin containing } t \text {-complex } \\
\text { protein } 1 \text {, theta subunit, tcpq }\end{array}$ & Up & - \\
\hline 56 & A0A095AUU9 & T-complex protein 1 subunit zeta & Up & - \\
\hline 57 & A0A095CBQ7 & T-complex protein 1 subunit theta & $\mathrm{Up}$ & - \\
\hline 58 & A9CBJ4 & DNA repair protein & $\mathrm{Up}$ & - \\
\hline 59 & Q26551 & Cyclophilin B & $\mathrm{Up}$ & - \\
\hline 60 & Q5DC69 & SJCHGC01960 protein, partial & Up & - \\
\hline 61 & Q5DDG6 & SJCHGC02536 protein & Up & - \\
\hline 62 & Q5DE64 & Unknown & Up & - \\
\hline 63 & Q5C3A0 & Unknown & Up & - \\
\hline 64 & Q5DGY1 & Unknown & $\mathrm{Up}$ & - \\
\hline 65 & C1L6Z6 & Mitochondrial processing peptidase & Down & - \\
\hline 66 & C1LNT2 & Serine protease inhibitor serpin & Down & - \\
\hline 67 & O45039 & HSP70, partial & Down & - \\
\hline 68 & C7TZI9 & Heat shock protein 90kDa alpha, partial & Down & - \\
\hline 69 & G4VJ99 & Putative heat shock protein & Down & - \\
\hline 70 & C1LEA0 & TNF receptor-associated protein 1 & Down & - \\
\hline 71 & Q06814 & Calreticulin & Down & - \\
\hline 72 & Q5BYY8 & SJCHGC04813 protein, partial & Down & - \\
\hline 73 & Q5C3 V3 & SJCHGC05011 protein, partial & Down & - \\
\hline 74 & Q5DBB0 & SJCHGC02058 protein & Down & - \\
\hline 75 & Q5DGD4 & SJCHGC06677 protein & Down & - \\
\hline 76 & Q5D9K8 & Unknown & Down & - \\
\hline
\end{tabular}


Table 5. Cont.

\begin{tabular}{ccccc}
\hline \multirow{2}{*}{ No. } & \multirow{2}{*}{$\begin{array}{c}\text { Accession } \\
\text { No. Uniprot }\end{array}$} & Protein Name & \multicolumn{2}{c}{ Status } \\
\cline { 3 - 5 } & Q5DBJ9 & Unknown & Expression & Phosphorylation \\
\hline 77 & G4LWI2 & Heat shock protein HSP60, putative & - \\
\hline 78 & Q8MXA4 & Heat shock protein HSP60, partial & - & Up \\
\hline 79 & Q5DGY9 & SJCHGC06312 protein & - & Up \\
\hline 80 & A0A094ZZQ1 & 60 kDa heat shock protein, mitochondrial & - & Up \\
\hline 81 & &
\end{tabular}

\subsection{Prediction of Key Kinases Effected by PZQ}

Phosphorylation of proteins in S. mekongi was strongly affected by PZQ, as shown by immunohistochemistry and phosphoproteomic analyses. Kinases are the key enzymes in the control of phosphorylation levels in cells and are known to be potential drug targets in several diseases. Using phosphopeptides and phosphorylation sites obtained from the MS results, it was possible to predict kinase-substrate interactions by the group-based prediction system. Phosphorylation data of calcium homeostasis, worm antigen, oxidative stress, protein folding, and proteolysis were subjected to kinase-substrate prediction to identify key kinases. Results showed 83 kinases (11 kinase groups) were involved in phosphorylation of proteins in these four pathways (Figure 7). Among the 83 kinases, proto-oncogene tyrosine-protein kinase Src, calcium/calmodulin-dependent protein kinase-like (CAMKL) and Wee protein kinase were the top three kinases controlling the pathways of interest (Table S3). Inhibition of these kinases would interfere with phosphorylation and signal transduction of calcium homeostasis, worm antigens, oxidative stress, protein folding and proteolysis pathways in a manner comparable to PZQ. Applying inhibitors of these kinases could therefore be an alternative means of schistosomiasis treatment.
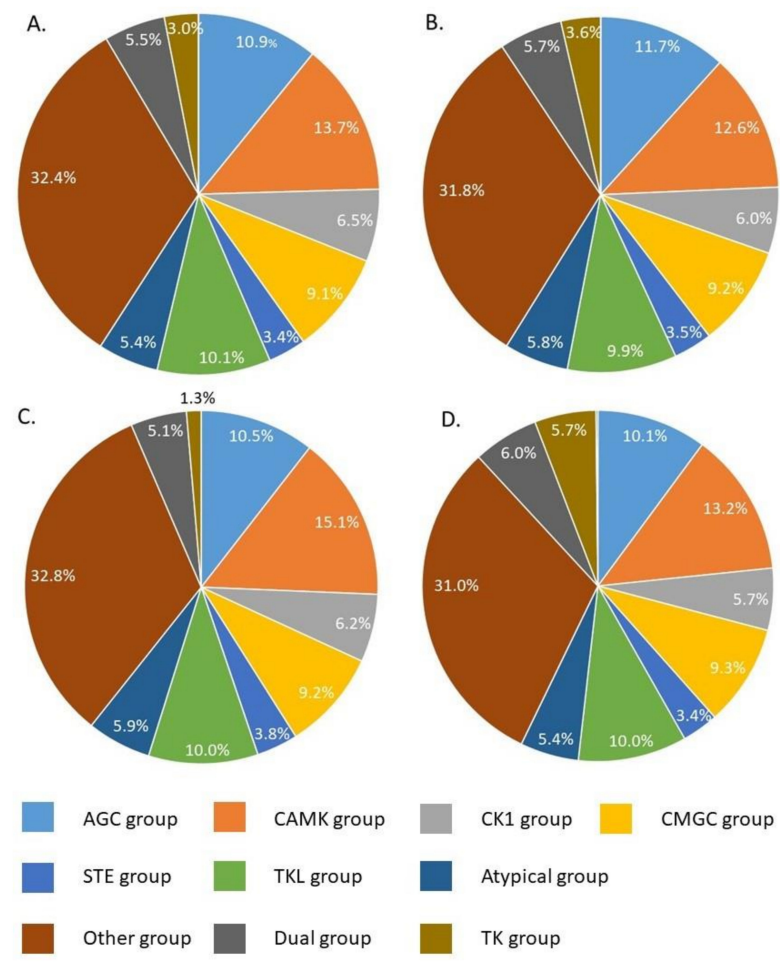

Figure 7. Distribution of kinase groups involved in protein phosphorylation in vital pathways of S. mekongi. Phosphopeptides identified from differential phosphoproteins were used to predict kinases corresponding for their phosphorylation with Group-based Prediction System. Percentage of phosphorylation sites for predicted kinases in (A) calcium homeostasis, (B) worm antigen, (C) oxidative stress and (D) proteins folding and proteolysis are shown. 


\section{Discussion}

S. mekongi is a public health threat in South-East Asia with PZQ currently the only drug of choice for treatment of this blood fluke. This study aimed to understand the parasiticidal mechanisms of PZQ on S. mekongi using proteomic and phosphoproteomic approaches. To study the parasiticidal effect of PZQ, $\mathrm{IC}_{50}$ was established by administering the drug to worms and observing for their movement. PZQ at $40 \mu \mathrm{g} / \mathrm{mL}$ killed $46.7 \%$ of adult worms and was defined as $\mathrm{IC}_{50}$ (Figure 1 ). In previous studies, the $\mathrm{IC}_{50}$ of PZQ varied from 0.03 to $80 \mu \mathrm{g} / \mathrm{mL}$ [29,32-34]. Duration of exposure could have an effect on $\mathrm{IC}_{50}$. Our study exposed adult worms to PZQ for $60 \mathrm{~min}$ before observing the mortality rates. This correlates with data indicating that PZQ starts to affect worms a few minutes after exposure [20]. The $60 \mathrm{~min}$ incubation period in this study could have allowed more time for the drug to penetrate into the worms to disrupt their protein moieties.

Several studies have proposed mechanisms of action of PZQ on schistosome. However, the exact molecular mechanism of PZQ against Schistosoma spp. is still unclear. High-throughput technologies were applied to Schistosoma parasite with reduced susceptibility to PZQ for elucidating its mechanism of action. Proteomic analysis of less-susceptible S. mansoni to PZQ revealed the upregulation of 2 proteins; heat shock protein 70 and calcium ATPase 2 protein [35]. Our study found altered expression of the same protein or proteins with similar function; heat shock protein 70 (O45039) and sodium/potassium-transporting ATPase subunit alpha (A0A095AFH4, A0A094ZR23) (Tables S1 and S2). Furthermore, gene expression profiling of less-susceptible parasite indicated a list of gene involving with calcium signaling pathway (calcium binding protein, calmodulin, calponin) and oxidative stress response (thioredoxin and superoxide dismutase) [36]. Our mass spectrometric data also found proteins in those pathways, which were $20 \mathrm{kDa}$ calcium-binding protein (A0A095A3D3), putative annexin (G4VL68), voltage-dependent anion-selective channel protein (VDAC) (G4M1U8) for calcium signaling pathway and tryparedoxin peroxidase (C1LV40), glutathione-S-transferase (Q26513) for oxidative stress pathway (Table 5). The mechanisms of action of PZQ have been continuously investigated. The interference of the calcium signaling pathway is one of the putative PZQ mechanisms of schistosome $[7,20,21,37,38]$. Pharmacologically, PZQ induces calcium influx to worm myocytes and contraction of musculature, leading to paralysis and loss of worm movement [20,21]. Voltage-gated calcium channels have been proposed as potential targets for PZQ by interfering with the interaction of the $\alpha$ and $\beta$ subunit of the proteins, thereby causing excessive uptake of calcium into cells [21,39]. Our MS results revealed the alteration of proteins involving in calcium signaling and interaction, such as the $20 \mathrm{kDa}$ calcium-binding protein (A0A095A3D3), putative annexin (G4VL68) and voltage-dependent anion-selective channel protein (VDAC) (G4M1U8) (Table 5). VDAC controls calcium movement between the mitochondria and cytoplasm; inhibition of this protein causes apoptosis and has been used as a drug target for cancer treatment [40,41]. Therefore, alteration of calcium homeostasis is strongly suggested as one of the parasiticidal mechanisms of PZQ. Another parasiticidal mechanism of PZQ against schistosome is the increased susceptibility of the parasite to host immunity by exposing antigens on worm surface [20]. Antibody and cell-mediated immunity significantly impact the killing ability of PZQ [20,23]. PZQ was less effective against $S$. mansoni in T cell-deprived hosts than normal hosts [42]. Immunization of mice with worm antigens enhanced the worm-killing effect of PZQ [43]. The studies stated that the worm antigens and host immunity play important roles in the parasiticidal ability of PZQ on schistosome, although the detailed mechanism is still unknown. Our findings found that expression of several antigenic proteins increased after PZQ treatment, including $55 \mathrm{kDa}$ antigen myophilin (Q86DV9) (Table 5), which may play some role in the effects of PZQ. Oxidative stress induction was also proposed as a mechanism of PZQ to parasitic worms [24,44]. The pathway for PZQ to induce oxidative stress in parasite is still unknown, although schistosome and other parasitic flatworms increased expression of antioxidants in response to PZQ [24,37,44,45]. Our study indicated that PZQ treatment increased expression of antioxidant proteins, such as tryparedoxin peroxidase (C1LV40) and glutathione-S-transferase (Q26513). In addition, phosphorylation of thioredoxin peroxidase (O97161), $26 \mathrm{kDa}$ glutathione-S-transferase (G4LXF8) and peroxiredoxin-2 (A0A095A0V3) were altered (Table 5). 
Our findings also revealed a potential novel mechanism of PZQ: the alteration of protein folding and proteolysis through the ERAD pathway. The function of the ERAD pathway is to eliminate unfolded/misfolded proteins from the ER through a series of proteins and phosphoproteins [46]. ERAD tags unfolded/misfolded proteins with ubiquitin prior to sending them for proteasome-mediated degradation [47]. Precise activity of ERAD is crucial for quality control of structure and function of the protein repertoire [48]. Interruption of ERAD could cause the accumulation of toxic proteins, apoptosis and cell death, which has been implicated in many diseases, such as Alzheimer's disease, Parkinson's disease and rheumatoid arthritis [47,48]. In Trypanosoma brucei, ERAD plays important roles in the processing of antigenic variation for host immune evasion [49]. T. brucei is believed to survive in extreme stress conditions, such as blood, by using unique ERAD mechanisms to shift their surface antigens and avoid detection by the immune system [46,49]. Moreover, Plasmodium falciparum showed sensitivity to ERAD inhibitor treatment. Therefore, proteins in ERAD may be novel targets for malarial drug development $[50,51]$. Unlike blood-dwelling protozoa, the process of antigenic variation of schistosome is manipulated by alternative splicing of micro-exon genes [52,53]. Although the schistosome ERAD pathway has never been studied before, protein break down and degradation was proposed as drug target for schistosomiasis treatment in a previous study [54]. Here, we propose that PZQ exerts its effect by interfering with the ERAD pathway of $S$. mekongi.

Phosphorylation is a vital molecular process for blood fluke biology, the alteration of which affects the viability of the worms. Our immunogold labeling to phosphoserine showed an overall reduction of phosphorylation levels after PZQ treatment (Figure 3). This present study found changes of a number of phosphoproteins after PZQ treatment. However, none of target validation was performed which is the limitation of this study. In addition, the inhibition of specific kinases, protein kinase C (PKC) and extracellular signal-regulated kinases, resulted in a reduction of protein phosphorylation and decreases in attachment, muscular activity, neuromuscular coordination, pairing and reproductive function of schistosomes [26]. Recently, drugs acting on phosphorylation and protein kinases have been proposed as novel targets for schistosomiasis treatment $[25,26,55-57]$. Kinomic array of $S$. mansoni revealed a number of kinases those are vital for Schistosoma biology [31] in which Src kinase, Cyclin-dependent kinase (CDK), PKC were predicted from bioinformatic tool as the critical kinases for anthelminthic effects of PZQ (Table S3). Our study indicates that kinases of critical pathways in the parasite and Src kinase are important kinases for PZQ response (Figure S1, Table S3). Src kinase is a cytoplasmic tyrosine kinase that controls diverse cellular processes, including adhesion, proliferation and differentiation [25]. Only a few studies have focused on the inhibition of Src kinase in schistosomes. An inhibitor of Src kinase, Herbimycin A, suppresses the mitotic activity and egg production of female schistosome, resulting in reduced reproductive capacity of worms [58]. As a consequence, Src kinase was proposed as novel target for the future development of antischistosomal drugs.

In summary, $\mathrm{PZQ}$ at $\mathrm{IC}_{50}$ caused a general reduction of protein phosphorylation in S. mekongi. PZQ also altered expression and phosphorylation of many proteins in key pathways of the parasites, including calcium homeostasis, worm antigens and oxidative stress. Moreover, the differentially expressed and phosphorylated proteins indicated that PZQ interferes with protein folding and proteolysis through the ERAD pathway. Furthermore, kinases responsible for phosphorylation of previously identified pathways were predicted and Src kinase was found to be the main enzyme influenced in the four pathways of interest. Our findings suggest a novel effect of PZQ as well as indicating possible drug targets, which could be used for the treatment of Mekong schistosomiasis in the future.

\section{Materials and Methods}

\subsection{S. mekongi Life Cycle Maintenance, Animal Husbandry and Worm Collection}

The life cycle of S. mekongi was maintained using snail Neotricula aperta as an intermediate host and mice Mus musculus as definitive hosts, as described earlier [59]. The snails were primarily collected 
from Mekong River in northeastern Thailand and cultured at the Applied Malacology Laboratory, Department of Social and Environmental Medicine, Faculty of Tropical Medicine, Mahidol University, Bangkok, Thailand. Eight-week-old female ICR mice were purchased from the National Laboratory Animal Center, Mahidol University. Mice were percutaneously infected with 25-30 cercariae of S. mekongi and housed in the Animal Care Unit, Faculty of Tropical Medicine, Mahidol University. Adult worms were collected at 8 weeks post-infection by hepatic perfusion with sterile $0.85 \%$ saline solution and subsequently cultured in Roswell Park Memorial Institute (RPMI) medium (Hyclone, GE Healthcare, Little Chalfont, UK) with 10\% fetal calf serum (Hyclone) in a humidified $5 \% \mathrm{CO}_{2}$ incubator at $37^{\circ} \mathrm{C}$ until PZQ treatment.

All experiments involving animals were performed according to the ethical principles and guidelines for the use of animals at the National Research Council of Thailand (NRCT). In addition, all procedures were conducted with the permission from the Faculty of Tropical Medicine Animal Care and Use Committee (FTM-ACUC), Mahidol University, with approval number FTM-ACUC 014/2016.

\subsection{PZQ Treatment and Half Maximal Inhibitory Concentration (IC $\left.{ }_{50}\right)$ Assessment}

PZQ (Tokyo Chemical Industry, Tokyo, Japan) was mixed with Dimethyl sulfoxide (DMSO) prior to diluted with RPMI medium to concentrations of $0,20,40,60,80$ and $100 \mu \mathrm{g} / \mathrm{mL}$ and administered for an hour to 10 pairs of $S$. mekongi for each concentration (three biologic replicates for each concentration). Worm movement was used as the indicator for viability. Periodic movement of the worms was observed under a video microscope (Celestron, CA, USA) at 0, 5, 10, 15, 30 and $60 \mathrm{~min}$ and worms that did not move after a minute of observation were identified as dead. After 1 hour of PZQ treatment, all worms were collected and kept at $-80{ }^{\circ} \mathrm{C}$ for further experiments. Data on worm viability were plotted and statistical significance at 0.05 was calculated with ANOVA using SPSS for Windows version 15.0 (SPSS, Inc., Chicago, IL, USA). The concentration that gave approximately $50 \%$ viability was identified as $\mathrm{IC}_{50}$.

\subsection{Protein Extraction and Phosphoprotein Enrichment}

Protein extraction was performed within a week after PZQ treatment, using the frozen extraction method and phosphoprotein enrichment was performed using the TALON PMAC Magnetic Phospho Enrichment Kit (Takara, Shiga, Japan). First, 10 pairs of untreated and $40 \mu \mathrm{g} / \mathrm{mL}-\mathrm{PZQ}$-treated worms were put into a mortar and homogenized in liquid nitrogen. After the nitrogen had completely evaporated, lysis buffer (provided with the kit) was added and incubated on ice for $10 \mathrm{~min}$. Protein lysate was transferred into tubes and centrifuged at $5000 \times g$ for 5 min at $4{ }^{\circ} \mathrm{C}$. The supernatant was transferred to new tube and the protein concentration was measured using the bicinchoninic acid (BCA) assay (Thermo Fisher Scientific, Waltham, MA, USA).

Phosphoprotein enrichment was performed according to manufacturer's protocol. Briefly, $250 \mu \mathrm{g}$ protein was mixed with metal ion-coated magnetic beads and mixed on a rotary shaker for 90 min at $4{ }^{\circ} \mathrm{C}$. The supernatant was discarded, and proteins bound to beads were eluted using $75 \mu \mathrm{L}$ of the provided elution buffer. Successful enrichment was confirmed using $12 \%$ sodium dodecyl sulfate-polyacrylamide gel electrophoresis (SDS-PAGE) and Pro-Q diamond staining (Thermo Fisher Scientific). All experiments were performed in three biologic replicates.

\subsection{Protein Separation and In-Gel Digestion}

For proteomic analysis, $50 \mu \mathrm{g}$ of sample was analyzed by SDS-PAGE and resulting protein bands were visualized using Coomassie Blue $\mathrm{G}$ staining. For phosphoproteomic analysis, $15 \mu \mathrm{L}$ of eluted sample was analyzed by SDS-PAGE gel and protein bands were visualized using silver staining. Thereafter protein bands from each lane were cut into small pieces for further in-gel digestion.

Coomassie dye was removed by incubating gels with $25-\mathrm{mM}$ ammonium bicarbonate buffer containing $50 \%$ acetonitrile. Silver stain was removed with $30-\mathrm{mM}$ potassium ferricyanide and 156-mM sodium thiosulfate in a 1:1 ratio. Gel pieces were then reduced with 4-mM dithiothreitol (Sigma-Aldrich, St. Louis, MO, USA) in 50-mM ammonium bicarbonate buffer, further alkylated 
with 250-mM iodoacetamide (Sigma-Aldrich) and dehydrated with 100\% acetonitrile. Proteins were digested overnight with $10 \mathrm{ng}$ trypsin (Sigma-Aldrich) dissolved in $200 \mu \mathrm{L}$ of 50-mM ammonium bicarbonate buffer containing $5 \%$ acetonitrile. After digestion, peptides were extracted by adding $200 \mu \mathrm{L}$ of acetonitrile. The supernatant containing eluted peptides was transferred to a new tube and dried using a speed vacuum, before being dissolved with $0.1 \%$ formic acid.

\subsection{Protein Identification by MS}

Peptide samples were analyzed using an UltiMate 3000 nano-liquid chromatography system (Thermo Fisher Scientific) coupled with a micrOTOF-Q electrospray ionization quadrupole time-of-flight MS (Bruker Daltonics, Billerica, MA, USA). Mobile phase A for sample injection was $2 \%$ acetonitrile and $0.1 \%$ formic acid in water and mobile phase $\mathrm{B}$ was $0.1 \%$ formic acid in acetonitrile with flow rate of $300 \mathrm{~nL} / \mathrm{min}$ for $60 \mathrm{~min}$. Data acquisition was performed using Hystar software (Bruker Daltonics). Spectra of the peptide covered mass ranges of $m / z 400-3000$ and $50-1500$.

\subsection{Data Analysis and Pathway Enrichment}

Data from all gel pieces were merged into single Mascot generic file (.mgf) using MASCOT DEMON (Matrix Science, London, UK), which was then searched for S. mekongi proteins using an in-house transcriptome database with missed cleavages allowed [59]. Peptide tolerance was assigned to $200 \mathrm{ppm}$ and the tandem MS tolerance was assigned to 0.6 Da. Methionine oxidation, cysteine carbamidomethylation, serine phosphorylation, tyrosine phosphorylation and threonine phosphorylation were identified as variable modifications. Proteins that showed differential expression or phosphorylation of more than 2-fold were selected for further pathway enrichment using BLAST2GO and KEGG Automatic Annotation Server (KAAS) applications.

BLAST2GO Version 5.2.3 (BioBam Bioinformatics, Valencia, Spain) was used to annotate sequences of differentially expressed or phosphorylated proteins according to their biologic processes, molecular function and subcellular localization with standard parameters [60]. Furthermore, protein sequences were analyzed and mapped into the KEGG Pathway using KEGG Automatic Annotation Server (KAAS: https://www.genome.jp/kegg/kaas/) with standard parameters [61]. The top 20 annotated pathways were shown, and pathways related to the effects of PZQ were presented with identified proteins highlighted.

\subsection{Phosphorylation Level Investigation by Immunogold Labeling and Transmission Electron Microscope (TEM)}

Phosphorylation levels of untreated and $40 \mu \mathrm{g} / \mathrm{mL}-\mathrm{PZQ}$-treated S. mekong $i$ were assessed by phosphoserine immunogold labeling and TEM. Briefly, worms with and without treatment were fixed using $2.5 \%$ glutaraldehyde in $0.1 \mathrm{M}$ sucrose phosphate buffer (SPB), pH 7.4, for an hour and subsequently washed 3 times with SPB for $10 \mathrm{~min}$. Worm samples were fixed with secondary fixative $1 \%$ osmium tetroxide and dehydrated in graded ethanol. Samples were immersed in a series of LR white resin (Electron Microscopy Sciences, PA, USA) before embedding in pure LR white (Electron Microscopy Sciences) and polymerizing at $60{ }^{\circ} \mathrm{C}$ for $48 \mathrm{~h}$. Sample blocks were cut into 100-nm-thick sections for further immunogold labeling.

Worm sections were initially blocked with 50-mM glycine in phosphate-buffered saline (PBS) and then with 5\% bovine serum albumin (BSA) (Electron Microscopy Sciences) in PBS for 30 min each. Sections were incubated with primary antibody against phosphoserine (Merck, Darnstadt, Germany) for 1 hour, followed by washing three times with $0.1 \%$ BSA in PBS. Sections were incubated with secondary antibody conjugated with 10-nm gold particles (Electron Microscopy Sciences). After washing three times, a silver enhancement kit (Electron Microscopy Sciences) was used to improve the contrast of gold particle labeling. Finally, sections were stained with lead citrate and uranyl acetate prior to visualization in a HT7700 model TEM (Hitachi, Tokyo, Japan). The labeled gold particles were examined throughout the parasite body, especially on tegument, muscle and internal cells. 


\subsection{Kinase Prediction for Identified Pathways}

Kinases that participate in calcium homeostasis, worm antigen, oxidative stress, protein folding and proteolysis pathways were predicted using the bioinformatic tool Group-based Prediction System version 5.0 (http://gps.biocuckoo.cn/online.php). The phosphopeptide data were input and analyzed with standard settings [62]. Predicted kinases were categorized according to their group and the number and percentage of phosphorylation sites of each predicted kinase were calculated. The graphical summary of whole experiments in this study is presented in Figure 8.

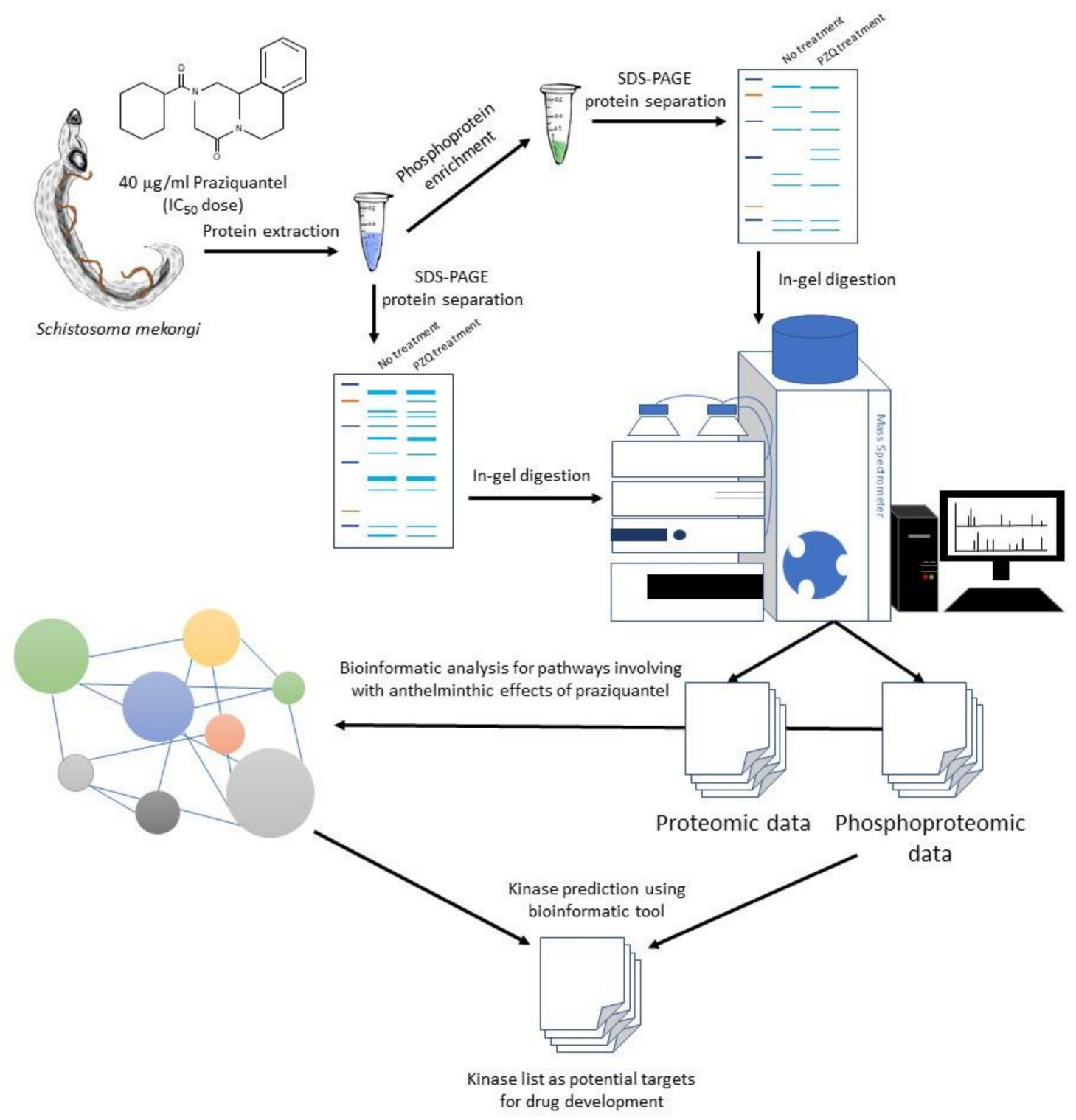

Figure 8. Graphical summary of the study. S. mekongi parasites were treated with $\mathrm{IC}_{50}$ dose of PZQ, anthelminthic drug. Protein lysate was extracted from untreated and PZQ-treated worms and subsequently enriched for phosphoproteins. Proteins and phosphoproteins were separated with $12 \%$ sodium dodecyl sulfate-polyacrylamide gel electrophoresis (SDS-PAGE) and protein bands were cut and digested by trypsin. Peptide was subjected to mass spectrometer for protein identification. Bioinformatics tools were used to analyze information from mass spectrometric data. Potential pathways involving with PZQ effects and kinases relating to those pathways were reported as possible targets for drug development. 
Supplementary Materials: The following are available online at http://www.mdpi.com/2076-0817/9/6/417/s1, Figure S1: Src kinase-substrate prediction from phosphopeptide data. Phosphopeptide data were used to predict kinases corresponding for their phosphorylation with Group-based Prediction System. Protein substrates of Src kinase are shown with number of phosphorylation sites and pathways. Src kinase was predicted to phosphorylate 85 sites of 14 proteins involved in calcium homeostasis, worm antigen, oxidative stress and proteins folding and proteolysis; Video S1: Movement of S. mekongi without PZQ treatment; Video S2: Movement of S. mekongi after treatment with $40 \mu \mathrm{g} / \mathrm{mL}$ of PZQ for $60 \mathrm{~min}$; Table S1: S. mekongi proteins upregulated after $40 \mu \mathrm{g} / \mathrm{mL}-\mathrm{PZQ}$ treatment; Table S2: S. mekongi proteins downregulated after $40 \mu \mathrm{g} / \mathrm{mL}-\mathrm{PZQ}$ treatment; Table S3: Top 25 predicted kinases responsible for phosphorylation of proteins involved in calcium binding, worm antigen, oxidative stress, protein folding and proteolysis.

Author Contributions: Conceptualization, P.A., Y.L. and O.R.; methodology, O.R.; investigation, Y.L., P.C., Y.C., P.C., T.T., S.A., and, O.R.; formal analysis, P.C.; writing-original draft preparation, P.C.; writing-review \& editing, O.R. and P.C.; supervision, O.R.; funding acquisition, O.R. and P.C. All authors have read and agreed to the published version of the manuscript.

Funding: This study was supported by the Goal-oriented Research Project Grant 2016 of Mahidol University through Onrapak Reamtong and Chulabhorn Royal Academy to Peerut Chienwichai.

Acknowledgments: We thank the Department of Molecular Tropical Medicine and Genetics and Central Equipment Unit, Faculty of Tropical Medicine, Mahidol University for providing the equipment and facilities. We also express our gratitude to Department of Helminthology, Applied Malacology Laboratory, Department of Social and Environmental Medicine and Animal Care Unit, Faculty of Tropical Medicine, Mahidol University for their support for animal experiment and parasite preparation.

Conflicts of Interest: The authors declare no conflict of interest.

\section{References}

1. World Health Organization. Schistosomiasis. Available online: https://www.who.int/en/news-room/factsheets/detail/\%20schistosomiasis. (accessed on 18 May 2019).

2. Adenowo, A.F.; Oyinloye, B.E.; Ogunyinka, B.I.; Kappo, A.P. Impact of human schistosomiasis in sub-Saharan Africa. Braz. J. Infect Dis. 2015, 19, 196-205. [CrossRef] [PubMed]

3. Campa, P.; Develoux, M.; Belkadi, G.; Magne, D.; Lame, C.; Carayon, M.J.; Girard, P.M. Chronic Schistosoma mekongi in a traveler-A case report and review of the literature. J. Travel Med. 2014, 21, 361-363. [CrossRef] [PubMed]

4. Pilsczek, F.H. Infectious diseases of Khmer immigrants in the United States: Review of published reports. J. Ayub Med. Coll. Abbottabad 2011, 23, 149-152. [PubMed]

5. Leshem, E.; Meltzer, E.; Marva, E.; Schwartz, E. Travel-related schistosomiasis acquired in Laos. Emerg. Infect. Dis. 2009, 15, 1823-1826. [CrossRef] [PubMed]

6. Ohmae, H.; Sinuon, M.; Kirinoki, M.; Matsumoto, J.; Chigusa, Y.; Socheat, D.; Matsuda, H. Schistosomiasis mekongi: From discovery to control. Parasitol. Int. 2004, 53, 135-142. [CrossRef] [PubMed]

7. Silva, V.; Campos, B.; Oliveira, J.F.; Decout, J.L.; Lima, M. Medicinal chemistry of antischistosomal drugs: Praziquantel and oxamniquine. Bioorg. Med. Chem. 2017, 25, 3259-3277. [CrossRef]

8. $\quad$ Lovis, L.; Mak, T.K.; Phongluxa, K.; Soukhathammavong, P.A.; Vonghachack, Y.; Keiser, J.; Vounatsou, P.; Tanner, M.; Hatz, C.; Utzinger, J.; et al. Efficacy of praziquantel against Schistosoma mekongi and Opisthorchis viverrini: A randomized, single-blinded dose-comparison trial. PLoS Negl. Trop. Dis. 2012, 6, e1726. [CrossRef]

9. Albonico, M.; Levecke, B.; LoVerde, P.T.; Montresor, A.; Prichard, R.; Vercruysse, J.; Webster, J.P. Monitoring the efficacy of drugs for neglected tropical diseases controlled by preventive chemotherapy. J. Glob. Antimicrob. Resist. 2015, 3, 229-236. [CrossRef]

10. Cioli, D.; Pica-Mattoccia, L.; Basso, A.; Guidi, A. Schistosomiasis control: Praziquantel forever? Mol. Biochem. Parasitol. 2014, 195, 23-29. [CrossRef]

11. Greenberg, R.M. New approaches for understanding mechanisms of drug resistance in schistosomes. Parasitology 2013, 140, 1534-1546. [CrossRef]

12. Melman, S.D.; Steinauer, M.L.; Cunningham, C.; Kubatko, L.S.; Mwangi, I.N.; Wynn, N.B.; Mutuku, M.W.; Karanja, D.M.S.; Colley, D.G.; Black, C.L.; et al. Reduced susceptibility to praziquantel among naturally occurring Kenyan isolates of Schistosoma Mansoni. PLoS Negl. Trop. Dis. 2009, 3, e504. [CrossRef] [PubMed]

13. Ismail, M.; Botros, S.; Metwally, A.; William, S.; Farghally, A.; Tao, L.F.; Bennett, J.L.; Farghally, A.; Metwally, A. Resistance to praziquantel: Direct evidence from Schistosoma mansoni isolated from Egyptian villagers. Am. J. Trop. Med. Hyg. 1999, 60, 932-935. [CrossRef] [PubMed] 
14. Seto, E.Y.W.; Wong, B.K.; Lu, D.; Zhong, B. Human Schistosomiasis resistance to praziquantel in China: Should we be worried? Am. J. Trop. Med. Hyg. 2011, 85, 74-82. [CrossRef] [PubMed]

15. King, C.H.; Muchiri, E.M.; Ouma, J.H. Evidence against rapid emergence of praziquantel resistance in Schistosoma haematobium, Kenya. Emerg. Infect. Dis. 2000, 6, 585-594. [CrossRef]

16. Chelladurai, J.J.; Kifleyohannes, T.; Scott, J.; Brewer, M.T. Praziquantel resistance in the zoonotic cestode Dipylidium caninum. Am. J. Trop. Med. Hyg. 2018, 99, 1201-1205. [CrossRef]

17. Lateef, M.; Zargar, S.A.; Khan, A.R.; Nazir, M.; Shoukat, A. Successful treatment of niclosamide- and praziquantel-resistant beef tapeworm infection with nitazoxanide. Int. J. Infect. Dis. 2008, 12, 80-82. [CrossRef]

18. McManus, D.P.; Dunne, D.W.; Sacko, M.; Utzinger, J.; Vennervald, B.J.; Zhou, X. Schistosomiasis. Nat. Rev. Dis. Primers 2018, 4. [CrossRef]

19. Siqueira, L.P.; Fontes, D.A.F.; Aguilera, C.S.B.; Timóteo, T.R.R.; Ângelosa, M.A.; Silva, L.; De Melo, C.G.; Rolim, L.A.; Da Silva, R.M.F.; Neto, P.J.R. Schistosomiasis: Drugs used and treatment strategies. Acta. Trop. 2017, 176, 179-186. [CrossRef]

20. Chai, J.Y. Praziquantel treatment in trematode and cestode infections: An update. Infect. Chemother. 2013, 45, 32-43. [CrossRef]

21. Chan, J.D.; Zarowiecki, M.; Marchant, J.S. $\mathrm{Ca}^{2+}$ channels and Praziquantel: A view from the free world. Parasitol. Int. 2013, 62, 619-628. [CrossRef]

22. Andrew, P. Praziquantel: Mechanism of anti-schistosomal activity. Pharm. Ther. 1985, 29, 129-156. [CrossRef]

23. Brindley, P.J.; Strand, M.; Norden, A.P.; Sher, A. Role of host antibody in the chemotherapeutic action of praziquantel against Schistosoma mansoni: Identification of target antigens. Mol. Biochem. Parasitol. 1989, 34, 99-108. [CrossRef]

24. Aragon, A.D.; Imani, R.A.; Blackburn, V.R.; Cupit, P.M.; Melman, S.D.; Goronga, T.; Webb, T.; Loker, E.S.; Cunningham, $\mathrm{C}$. Towards an understanding of the mechanism of action of praziquantel. Mol. Biochem. Parasitol. 2009, 164, 57-65. [CrossRef] [PubMed]

25. Dissous, C.; Ahier, A.; Khayath, N. Protein tyrosine kinases as new potential targets against human schistosomiasis. BioEssays 2007, 29, 1281-1288. [CrossRef]

26. Ressurreicao, M.; Saram, P.; Kirk, R.S.; Rollinson, D.; Emery, R.M.; Page, N.M.; Davies, A.J.; Walker, A.J. Protein kinase $\mathrm{C}$ and extracellular signal-regulated kinase regulate movement, attachment, pairing and egg release in Schistosoma mansoni. PLoS Negl. Trop. Dis. 2014, 8, e2924. [CrossRef]

27. You, H.; McManus, D.P.; Hu, W.; Smout, M.J.; Brindley, P.J.; Gobert, G.N. Transcriptional responses of in vivo praziquantel exposure in schistosomes identifies a functional role for calcium signalling pathway member CamKII. PLoS Pathog. 2013, 9, e1003254. [CrossRef]

28. Duan, O.; Zhao, H.; Zhang, Z.; Li, H.; Wu, H.; Shen, Q.; Wang, C.; Yin, T. Mechanistic evaluation and translational signature of gemcitabine-induced chemoresistance by quantitative phosphoproteomics analysis with iTRAQ labeling mass spectrometry. Sci. Rep. 2017, 7, 12891. [CrossRef]

29. Ctortecka, C.; Palve, V.; Kuenzi, B.M.; Fang, B.; Sumi, N.J.; Izumi, V.; Novakova, S.; Kinose, F.; Rix, L.L.R.; Haura, E.B.; et al. Functional proteomics and deep network interrogation reveal a complex mechanism of action of midostaurin in lung cancer cells. Mol. Cell Proteom. 2018, 17, 2434-2447. [CrossRef]

30. Bernardini, G.; Laschi, M.; Serchi, T.; Spreafico, B.; Botta, M.; Schenone, S. Proteomics and phosphoproteomics provide insights into the mechanism of action of a novel pyrazolo [3,4-d] pyrimidine Src inhibitor in human osteosarcoma. Mol. BioSyst. 2014, 10, 1305-1312. [CrossRef]

31. Hirst, N.L.; Nebel, J.C.; Lawton, S.P.; Walker, A.J. Deep phosphoproteome analysis of Schistosoma mansoni leads development of a kinomic array that highlights sex-biased differences in adult worm protein phosphorylation. PLoS Negl. Trop. Dis. 2020, 14, e0008115. [CrossRef]

32. Corrêa, S.; Oliveira, R.N.; Mendes, T.M.F.; Santos, K.R.; Boaventura, S.B., Jr.; Garcia, V.L.; Jeraldo, V.D.L.S.; Allegretti, S.M. In vitro and in vivo evaluation of six artemisinin derivatives against Schistosoma mansoni. Parasitol. Res. 2019, 118, 505-516. [PubMed]

33. Kovač, J.; Vargas, M.; Keiser, J. In vitro and in vivo activity of R- and S-praziquantel enantiomers and the main human metabolite trans-4-hydroxypraziquantel against Schistosoma haematobium. Parasit. Vectors 2017, 10. [CrossRef]

34. Pica-Mattoccia, L.; Cioli, D. Sex- and stage-related sensitivity of Schistosoma mansoni to in vivo and in vitro praziquantel treatment. Int. J. Parasitol. 2004, 34, 527-533. [CrossRef] [PubMed] 
35. Abou-El-Naga, I.F.; Amer, E.I.; Boulos, L.M.; El-Faham, M.H.; Abou Seada, N.M.; Younis, S.S. Biological and proteomic studies of Schistosoma mansoni with decreased sensitivity to praziquantel. Comp. Immunol. Microbiol. Infect. Dis. 2019, 66, 101341. [CrossRef]

36. Sanchez, M.C.; Cupit, P.M.; Bu, L.; Cunningham, C. Transcriptomic analysis of reduced sensitivity to praziquantel in Schistosoma Mansoni. Mol. Biochem. Parasitol. 2019, 228, 6-15. [CrossRef]

37. Cupit, P.M.; Cunningham, C. What is the mechanism of action of praziquantel and how might resistance strike? Future Med. Chem. 2015, 7, 701-705. [CrossRef]

38. Xiao, S.; Sun, J.; Chen, M. Pharmacological and immunological effects of praziquantel against Schistosoma japonicum: A scoping review of experimental studies. Infect. Dis. Poverty 2018, 7, 9. [CrossRef]

39. Kohn, A.B.; Roberts-Misterly, J.M.; Anderson, P.A.V.; Greenberg, R.M. Creation by mutagenesis of a mammalian $\mathrm{Ca}^{2+}$ channel b subunit that confers praziquantel sensitivity to a mammalian $\mathrm{Ca}^{2+}$ channel. Int. J. Parasitol. 2003, 33, 1303-1308. [CrossRef]

40. Shoshan-Barmatz, V.; De, S.; Meir, A. The mitochondrial voltage-dependent anion channel 1, Ca ${ }^{2+}$ transport, apoptosis and their regulation. Front. Oncol. 2017, 7. [CrossRef]

41. Ben-Hail, D.; Palty, R.; Shoshan-Barmatz, V. Measurement of mitochondrial $\mathrm{Ca}^{2+}$ transport mediated by three transport proteins: VDAC1, the $\mathrm{Na}^{+} / \mathrm{Ca}^{2+}$ exchanger and the $\mathrm{Ca}^{2+}$ uniporter. Cold Spring Harb. Protoc. 2014, 2, 161-166. [CrossRef]

42. Doenhoff, M.J.; Sabah, A.A.; Fletcher, C.; Webbe, G.; Bain, J. Evidence for an immune-dependent action of praziquantel on Schistosoma mansoni in mice. Trans. R. Soc. Trop. Med. Hyg. 1987, 81, 947-951. [CrossRef]

43. Fallon, P.G.; Doenhoff, M.J. Active immunization of mice with Schistosoma mansoni worm membrane antigens enhances efficacy of praziquantel. Parasite Immunol. 1995, 17, 261-268. [CrossRef] [PubMed]

44. Giri, B.R.; Roy, B. Praziquantel induced oxidative stress and apoptosis-like cell death in Raillietina echinobothrida. Acta Trop. 2016, 159, 50-57. [CrossRef] [PubMed]

45. Zhang, L.; Liu, F.; Cui, S.; Xu, B.; Zhou, X.; Hu, W. Proteomic analysis of adult Schistosoma japonicum treated with praziquantel. Zhongguo Ji Sheng Chong Xue Yu Ji Sheng Chong Bing Za Zhi 2008, 26, 258-262. [PubMed]

46. Manna, P.T.; Boehm, C.; Leung, K.F.; Natesan, S.K.; Field, M.C. Life and times: Synthesis, trafficking, and evolution of VSG. Trends Parasitol. 2014, 30, 251-258. [CrossRef] [PubMed]

47. Guerriero, C.J.; Brodsky, J.L. The delicate balance between secreted protein folding and endoplasmic reticulum-associated degradation in human physiology. Physiol. Rev. 2012, 92, 537-576. [CrossRef] [PubMed]

48. Printsev, I.; Curiel, D.; Carraway III, K.L. Membrane protein quantity control at the endoplasmic reticulum. J. Membr. Biol. 2017, 250, 379-392. [CrossRef]

49. Tiengwe, C.; Muratore, K.A.; Bangs, J.D. Variant Surface Glycoprotein, Transferrin Receptor, and ERAD in Trypanos. Brucei. Cell Microbiol. 2016, 18, 1673-1688. [CrossRef]

50. Chung, D.D.; Ponts, N.; Prudhomme, J.; Rodrigues, E.M.; Roch, K.G. Characterization of the ubiquitylating components of the human malaria parasite's protein degradation pathway. PLOS ONE 2012, 7, e43477. [CrossRef]

51. Harbut, M.B.; Patel, B.A.; Yeung, B.K.S.; McNamara, C.W.; Bright, A.T.; Ballard, J.; Supek, F.; Golde, T.E.; Winzeler, E.A.; Diagana, T.T.; et al. Targeting the ERAD pathway via inhibition of signal peptide peptidase for antiparasitic therapeutic design. Proc. Natl. Acad. Sci. USA 2012, 109, 21486-21491. [CrossRef]

52. Hull, R.; Dlamini, Z. The role played by alternative splicing in antigenic variability in human endo-parasites. Parasit Vectors 2014, 7. [CrossRef] [PubMed]

53. Marco, R.; Mathieson, W.; Manuel, S.J.; Dillon, G.P.; Curwen, R.S.; Ashton, P.; Ivens, A.; Berriman, M.; Verjovski-Almeida, S.; Wilson, R.A. Protein variation in blood-dwelling schistosome worms generated by differential splicing of micro-exon gene transcripts. Genome. Res. 2010, 20, 1112-1121.

54. Liu, S.; Cai, P.; Piao, X.; Hou, N.; Zhou, X.; Wu, C.; Wang, H.; Chen, Q. Expression profile of the Schistosoma japonicum degradome reveals differential protease expression patterns and potential anti-schistosomal intervention targets. PLoS Comput. Biol. 2014, 10, e1003856. [CrossRef] [PubMed]

55. Nawaratna, S.S.K.; You, H.; Jones, M.K.; McManus, D.P.; Gobert, G.N. Calcium and Ca ${ }^{2+} / C^{2}$ almodulindependent kinase II as targets for helminth parasite control. Biochem. Soc. Trans. 2018, 46, 1743-1751. [CrossRef]

56. Walker, A.J.; Ressurreição, M.; Rothermel, R. Exploring the function of protein kinases in schistosomes: Perspectives from the laboratory and from comparative genomics. Front. Genet. 2014, 5. [CrossRef] 
57. Avelar, L.G.A.; Nahum, L.A.; Andrade, L.F.; Oliveira, G. Functional diversity of the Schistosoma mansoni tyrosine kinases. J. Signal Transduct. 2011, 2011, 603290. [CrossRef]

58. Knobloch, J.; Kunz, W.; Grevelding, C.G. Herbimycin A suppresses mitotic activity and egg production of female Schistosoma mansoni. Int. J. Parasitol. 2006, 36, 1261-1272. [CrossRef]

59. Phuphisut, O.; Ajawatanawong, P.; Limpanont, Y.; Reamtong, O.; Nuamtanong, S.; Ampawong, S.; Chaimon, S.; Dekumyoy, P.; Watthanakulpanich, D.; Swierczewski, B.; et al. Transcriptomic analysis of male and female Schistosoma mekongi adult worms. Parasit. Vectors 2018, 11. [CrossRef]

60. Conesa, A.; Götz, S.; García-Gómez, J.M.; Terol, J.; Talón, M.; Robles, M. Blast2GO: A universal tool for annotation, visualization and analysis in functional genomics research. Bioinformatics 2005, 21, 3674-3676. [CrossRef]

61. Moriya, Y.; Itoh, M.; Okuda, S.; Yoshizawa, A.C.; Kanehisa, M. KAAS: An automatic genome annotation and pathway reconstruction server. Nucleic Acids Res. 2007, 35, W182-W185. [CrossRef]

62. Xue, Y.; Liu, Z.; Cao, J.; Ma, Q.; Gao, X.; Wang, Q.; Jin, C.; Zhou, Y.; Wen, L.; Ren, J. GPS 2.1: Enhanced prediction of kinase-specific phosphorylation sites with an algorithm of motif length selection. Protein. Eng. Des. Sel. 2011, 24, 255-260. [CrossRef] [PubMed]

(C) 2020 by the authors. Licensee MDPI, Basel, Switzerland. This article is an open access article distributed under the terms and conditions of the Creative Commons Attribution (CC BY) license (http://creativecommons.org/licenses/by/4.0/). 